
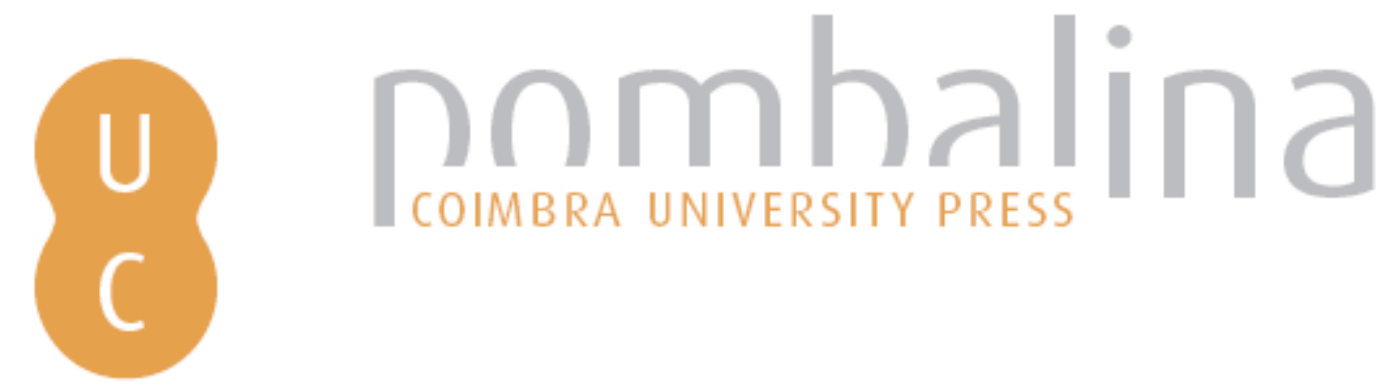

\title{
Wahrnehmung und Selbstreferenz: der selbstreferentielle Charakter der Wahrnehmung nach Hierokles
}
Autor(es):
Carvalho, M. Jorge de
Publicado por: Imprensa da Universidade de Coimbra
URL
persistente:
URI:http://hdl.handle.net/10316.2/31623
DOI:
DOI:http://dx.doi.org/10.14195/978-989-26-0205-9_6
Accessed : $\quad$ 26-Apr-2023 14:31:06

A navegação consulta e descarregamento dos títulos inseridos nas Bibliotecas Digitais UC Digitalis, UC Pombalina e UC Impactum, pressupõem a aceitação plena e sem reservas dos Termos e Condições de Uso destas Bibliotecas Digitais, disponíveis em https://digitalis.uc.pt/pt-pt/termos.

Conforme exposto nos referidos Termos e Condições de Uso, o descarregamento de títulos de acesso restrito requer uma licença válida de autorização devendo o utilizador aceder ao(s) documento(s) a partir de um endereço de IP da instituição detentora da supramencionada licença.

Ao utilizador é apenas permitido o descarregamento para uso pessoal, pelo que o emprego do(s) título(s) descarregado(s) para outro fim, designadamente comercial, carece de autorização do respetivo autor ou editor da obra.

Na medida em que todas as obras da UC Digitalis se encontram protegidas pelo Código do Direito de Autor e Direitos Conexos e demais legislação aplicável, toda a cópia, parcial ou total, deste documento, nos casos em que é legalmente admitida, deverá conter ou fazer-se acompanhar por este aviso.

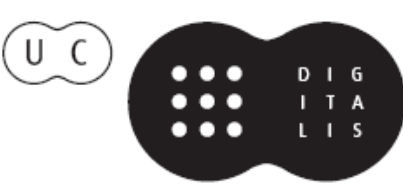


Edmundo Balsemão Pires

Burkhard Nonnenmacher

Stefan Büttner-von Stülpnagel

Editors

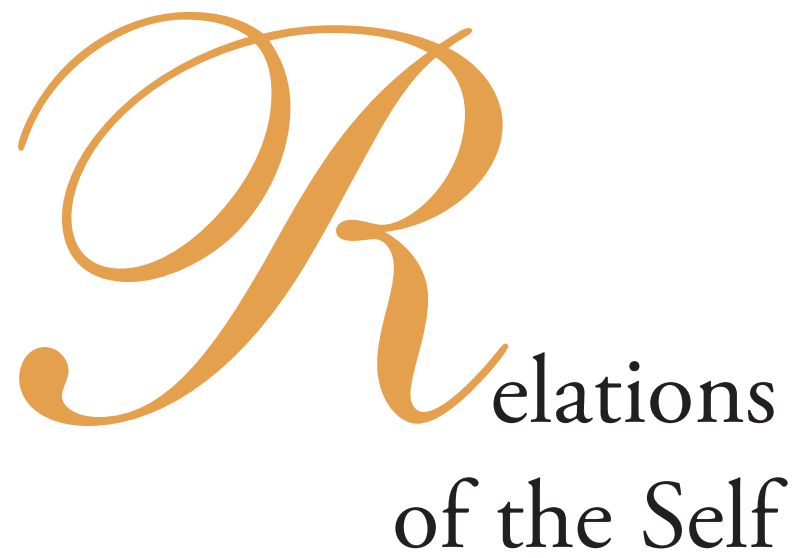




\section{Jorge de Carvalho \\ U. N. L. Lissabon}

\section{WAHRNEHMUNG UND SELBSTREFERENZ - DER SELBSTREFERENTIELLE CHARAKTER DER WAHRNEHMUNG NACH HIEROKLES}

\section{1-Einleitung}

Im Folgenden ist ausschließlich von Hierokles, dem Stoiker aus der Mitte des 2. Jahrhunderts nach Christus die Rede, wovon im voraus jedermann ausdrücklich verständigt sei, damit niemand später getäuschte Erwartungen einklagen könne. Ist es aber nicht grundverkehrt, immer wieder verstaubte, überalterte, ja abstruse Relikte aus der Geschichte der Philosophie auszugraben, anstatt sich direkt mit den philosophischen Fragen zu beschäftigen, damit diese endlich gelöst oder wenigstens ihrer Lösung nähergeführt werden? Und - was noch schlimmer ist - wenn man ehrlich sein will, muss man nicht von vornherein zugeben, dass der Begriff von Selbstbezug oder Selbstreferenz bei Hierokles überhaupt nicht belegt ist? Warum dann ein Vortrag zu diesem Thema?

Zur Beantwortung der ersten Frage, die man hier natürlich nicht ausführlich erörtern kann, sei an ein Wort Kants erinnert, der in den Reflexionen zur Anthropologie Folgendes schreibt: „Die Denkende[n] Köpfe gehören zu einer Gelehrten welt, die in ununterbrochnem Zusammenhange steht (es mögen auch einige Jahrhunderte einen Traum (schlaf) dazwischen ausmachen). Auf diese weise gehören die Alte zur jungen Gelehrten[-] oder denkenden Welt, die neuen zur Alten, wohl zu verstehen, wenn sie sich der Einsichten der jüngeren Welt zu Nutze machen. “1 In unserem Fall bedeutet dies, dass die „Altersfrage“ nicht das Wesentliche ist, und dass man schließlich aufhören soll, die Vorlage einer Art gültigen Modernitäts- oder Postmodernitätsausweises zu verlangen, so dass man philosophische Texte nur dann als solche ernstnimmt, d. h. als Forschungsprotokolle und erwägenswerte Beiträge zur Klärung der in ihnen erörterten Sachfragen betrachtet, wenn die fraglichen Texte diese voreingenommene (praeiudicium novitatis hieß es in der Vorurteilstheorie des 18. Jahrhunderts), mit einem hochbetagten Alter automatisch verbundene capitis deminutio nicht erleiden. Denn entscheidend ist nicht, wie alt die philosophischen Ideen oder Einsichten sind, sondern vielmehr, ob sie zur Klärung philosophischer Probleme beitragen, produktiv wirken und zu neuen Einsichten

\footnotetext{
${ }^{1}$ Kant, Refl. 1448a, $A A$ Bd. XV, S. 632-633.
} 
führen, d. h. ob sie dem entsprechen können, worauf ein Aphorismus aus Lichtenbergs Sudelbüchern hindeutet, der von so etwas wie „neuen Blicken durch alte Löcher“ spricht ${ }^{2}$.

Die zweite Frage kann ihrerseits nur dadurch beantwortet werden, dass man zeigt, 1) dass der Begriff von Selbstbezug oder Selbstreferenz bei Hierokles zwar nicht belegt ist, sich aber in seiner Argumentation der Sache nach ganz eindeutig abzeichnet, 2) dass dieser noch nicht ausgeführte, im Text des Hierokles nur in nuce liegende Begriff nichts Vereinzeltes, Zufälliges, nur mit Hilfe einer Lupe deutlich zu Erkennendes ist, sondern ganz im Gegenteil im Mittelpunkt seiner Betrachtungen steht - und zwar dergestalt, dass 3) die bei Hierokles zu findende Erörterung selbstreferentieller Phänomene immer noch anregend für die gegenwärtige Forschungssituation ist und in der Tat dazu verhelfen kann, einen Einblick in die Grundverfassung derartiger Phänomene zu gewinnen. Dies zu zeigen ist die Aufgabe meines Vortrages.

Einschränkend ist allerdings anzumerken, dass der im Folgenden unternommene Versuch sozusagen Stückwerk bleibt - nicht nur deswegen, weil man nur einen Teil des im Übrigen nur sehr bruchstückhaft erhaltenen Werks des Hierokles erörtern kann, sondern vor allen Dingen, weil die hier durchzuführende Betrachtung viele Aspekte völlig außer Acht lassen muss, die mit dem zur Erörterung Stehenden so eng verbunden sind, dass ihre Weglassung sowohl die bei Hierokles zu findende Erörterung der in diesem Vortrag behandelten Phänomene, als auch die fraglichen Phänomene selbst aus ihrem eigentlichen Zusammenhang herausreißt. Doch dies muss man wohl in Kauf nehmen. Denn die gewährte Zeit ist knapp, und man muss sich darauf beschränken, einen ersten Blick auf einen Problemzusammenhang zu werfen, dessen Auslotung letztendlich eine viel ausführlichere und umfangreichere Erörterung erfordern würde.

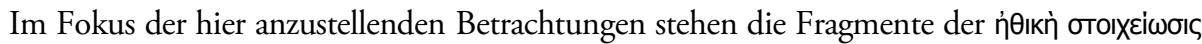
(d. h. der Grundlegung der Ethik) des Hierokles - oder, genauer gesagt, diejenigen Fragmente

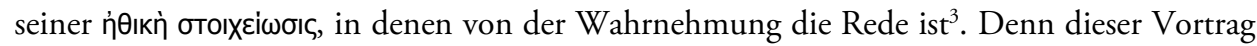
stellt sich lediglich die Aufgabe, Hierokles' Erörterung des selbstreferentiellen Charakters der Wahrnehmung zu untersuchen bzw. die Art und Weise herauszuarbeiten, wie Hierokles zu zeigen versucht hat, dass jeder Wahrnehmung ihrem Wesen nach eine Art Selbstbezug innewohnt, und zwar so, dass der fragliche Selbstbezug kein mehr oder weniger zufälliges, nebensächliches und unerhebliches Moment des Wahrnehmungsvorganges, sondern vielmehr eine unerlässliche Grundbedingung und Grundeigenschaft jeder Wahrnehmung als solcher darstellt. Ja, Hierokles zufolge verhält es sich so, dass jede Wahrnehmung von Grund auf in den Rahmen eines derartigen Selbstbezuges eingebettet und durch diesen selbstreferentiellen Zusammenhang dergestalt bedingt und strukturiert ist, dass im Grunde genommen all ihre Elemente von diesem selbstreferentiellen Charakter durch und durch geprägt sind. Das

${ }^{2}$ F879, in: G. C. Lichtenberg, Schriften und Briefe, hrsg. von W. Promies, München 1968, Bd. I, S. 585.

${ }^{3}$ Hierokles, Ethische Elementarlehre (Papyrus 9780) nebst den bei Stobäus erhaltenen ethischen Exzerpten aus Hierokles, hrsg. von H. von Arnim, Berlin 1906 sowie die neue Ausgabe von G. Bastianini und A. A. Long (Hrsg.), in: Corpus dei Papiri Filosofici Greci e Latini. Testi e lessico nei papiri di cultura greca e latina. Parte I: Autori noti, vol $1^{* *}$, Firenze 1992, S. 268-451. Als Text wird letztere Ausgabe zugrunde gelegt. Zur Datierungsfrage vgl. Karl Praechter, Hierokles der Stoiker, Leipzig 1901, G. Bastianini/A. Long, op. laud., S. 281f., P. Steinmetz, „Die Stoa“, in: H. Flashar (Hrsg.) Die Philosophie der Antike, Bd. 4, Die hellenistische Philosophie, Basel 1994, S. 491-716, bes. 499. 
Hauptaugenmerk liegt hierbei auf der Beantwortung folgender Fragen: 1. Wenn der Begriff von Selbstbezug bei Hierokles noch nicht belegt ist, wie drückt sich seine nur ansatzweise skizzierte bzw. angedeutete Auffassung des selbstreferentiellen Charakters der Wahrnehmung aus? 2. Was führt Hierokles dazu, auf eine Art von selbstreferentiellem Zusammenhang als Grundbedingung und Grundstruktur der Wahrnehmung hinzuweisen? 3. Wie ist der fragliche Selbstbezug u. d. h. zugleich, wie ist der Mittelpunkt des selbstreferentiellen Zusammenhangs, wie ist die Selbstinstanz: wie ist das Selbst beschaffen, das Hierokles zufolge jeder Wahrnehmung als solcher zugrunde liegt und für all ihre Momente so maßgebend ist, dass alles in der Wahrnehmung gleichsam um diesen Mittelpunkt kreist ${ }^{4}$ ?

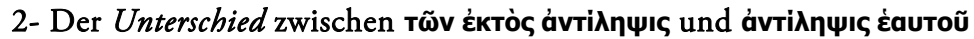

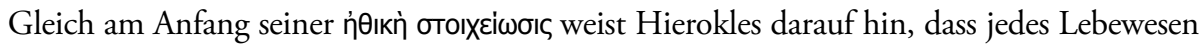
von dem Augenblick an, wo es geboren wird, mit Selbstwahrnehmung begabt ist, d. h.

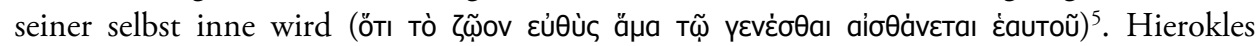
erinnert aber gleich daran, dass es doch Leute gibt, die überhaupt bezweifeln, dass ein

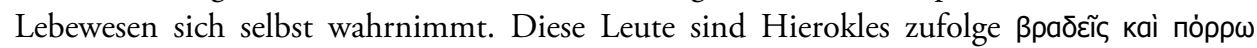

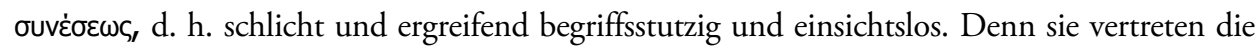
Auffassung, dass die Wahrnehmung dem Lebewesen von der Natur gegeben ist, nur damit

\footnotetext{
${ }^{4}$ Im Folgenden geht es nicht darum, die von Hierokles dargestellte Lehre doxographisch nachzuzeichnen. Es geht vielmehr darum, gewisse eigentümliche Züge seiner Erörterung der Wahrnehmungsphänomene in der n் отохвішбı hervorzuheben und die bahnbrechenden Einsichten herauszuarbeiten, auf die diese Züge der hierokleischen Erörterung der Wahrnehmung hindeuten. Mit anderen Worten, es geht darum, gewissen bei Hierokles zu findenden Ansätzen und Andeutungen etwas schärfere Konturen zu verleihen, um somit ein deutlicheres Bild dessen zu gewinnen, worauf die fraglichen Ansätze und Andeutungen letzten Endes hinweisen. Von der Frage, inwieweit Hierokles' Ausführungen sich durch ihre Originalität auszeichnen oder vielmehr einer unkritischen Darstellung orthodoxen stoischen Gedankengutes entsprechen, wird hier völlig abgesehen. Das Hauptaugenmerk wird ausschließlich auf die Tragweite und Leistungsfähigkeit der eigentümlichen Auffassung der Wahrnehmung gelegt, die sich in den Fragmenten des Hierokles abzeichnet.

${ }^{5}$ I, 37-39. Bezeichnend ist auch hier, dass Hierokles immer wieder vom $\zeta \tilde{\omega}$ ov spricht. Das mag auf den ersten Blick unbedeutend erscheinen, gewinnt aber bei näherer Betrachtung ein ganz anderes Gewicht. Denn die von Hierokles dargestellte Erörterung der Wahrnehmung zeichnet sich gerade dadurch aus, dass sie die Wahrnehmung als ein Grundphänomen des Lebens auffasst, welches nur als Moment des Lebens zu verstehen ist. D. h.: Das Leben stellt weit mehr als eine unerlässliche Bedingung des Wahrnehmungsvorganges dar, als ob dieser zwar nur in den Lebewesen stattfinden könnte, seinem Wesen und seiner Struktur nach aber besonderen, nur ihm eigentümlichen Gesetzen unterläge, die an und für sich mit dem Leben nichts zu tun haben. Es verhält sich vielmehr so, dass alle Wahrnehmung von Grund aus mit dem Leben aufs Innigste zusammenhängt, und zwar dergestalt, dass das Wesen und die Struktur, ja sämtliche Grundcharakteristika des Wahrnehmens diesen Zusammenhang mit dem ihm zugrunde liegenden Leben durchgängig widerspiegeln. Die Wahrnehmung bildet somit nichts Freischwebendes, Losgelöstes, Absolutes. Sie entstammt dem Leben und ist ihrer Natur nach in das Leben eingebunden: sie ist eine Erscheinungsform oder ein Bestandteil des Lebens. Und nur indem man sie als einen solchen versteht, gewinnt man einen angemessenen Einblick in ihr Wesen. Die entscheidende Frage ist dann allerdings, wie das Leben selbst zu verstehen ist, was das Leben als solches auszeichnet, und was die Tatsache, dass alle Wahrnehmung von Grund auf ein Moment des Lebens bildet, für die Bestimmung des Wesens und der Struktur der Wahrnehmung bedeutet. Von der Frage, ob die Wahrnehmung bzw. Selbstwahrnehmung erst mit der Geburt anfängt (das ist die stoische Lehre, die Hierokles ohne weiteres voraussetzt), oder vielmehr bereits im vorgeburtlichen Leben zu finden ist, wird hier völlig abgesehen.
} 
es zur Erfassung äußerer Gegenstände (тà غ̇ктós) nicht auch zur Erfassung seiner selbst (غ่autoũ) befähigt sei. ${ }^{6}$

Den Ausgangspunkt der hierokleischen Betrachtung bildet diese Gegenüberstellung von

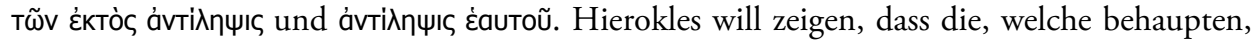
dass die Wahrnehmung wesensmäßig nach außen gerichtet ist, ausschließlich Außendinge (та̀ દ̇кто́s) zum Gegenstande hat (so dass es im Grunde keine Selbstwahrnehmung gibt), durch die Tatsachen Lügen gestraft werden. Dabei beruft er sich auf zahlreiche phänomenale Begebenheiten, um seine These unter Beweis zu stellen. Dies kann dazu verleiten, voreilig das von ihm vorgelegte Beweismaterial zu sichten, ehe man einige Fragen erörtert, ohne deren Klärung man Gefahr läuft, das Spezifikum seines Ansatzes und somit auch das eigentliche Ergebnis seiner Analysen zu verfehlen.

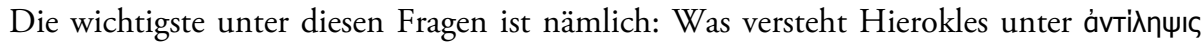
غ̇autoũ oder Selbstwahrnehmung? Gleich am Anfang gibt er uns einen aufschlußreichen, wenn

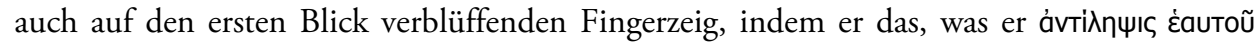
nennt, der Wahrnehmung gleichstellt, die jedes Lebewesen von seinen Gliedern hat (тò Tw̃v

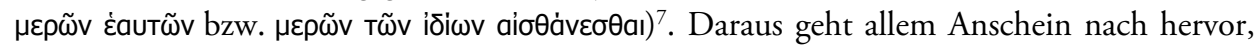
dass die Selbstwahrnehmung, von der bei Hierokles die Rede ist, irgendwie der Wahrnehmung des eigenen Leibes entspricht oder wenigstens etwas ist, zu dem die Wahrnehmung des eigenen Leibes gehört. Es ist somit ohne weiteres klar, dass der hier in Frage stehende

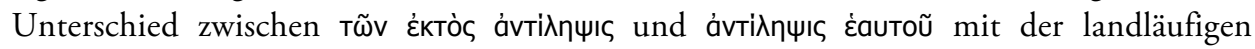
Gegenüberstellung von äußerer und innerer Wahrnehmung nicht das Geringste zu tun hat.

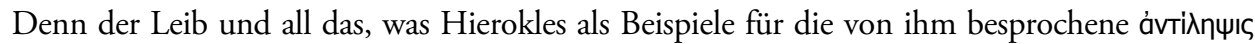
غ̇autoũ nennt, sind allem Anschein nach Gegenstände äußerer Wahrnehmung in dem üblichen Sinne. Die Trennlinie zwischen tà દ̇kтós, den Außendingen, und dem eigentümlichen

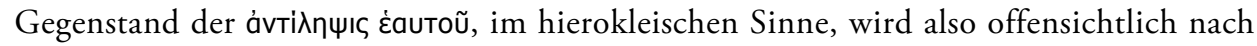
einem ganz anderen Kriterium gezogen. Es fragt sich aber: nach welchem?

Diese Frage lässt sich folgendermaßen beantworten: Die Selbstwahrnehmung im hierokleischen Sinne ist dadurch charakterisiert, dass sie die Gesamtheit der Vorstellungen bezeichnet, die das Wahrnehmende vom seinem eigenen Wesen hat. Das Spezifikum der

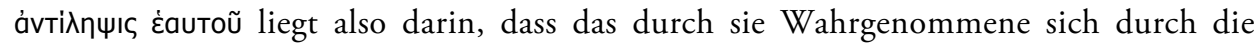
Grundbestimmung des Selbst oder durch den Grundcharakter des Eigenen auszeichnet. Das ist der Grund, warum der Leib, der im heute landläufigen Sinne nur als Gegenstand der

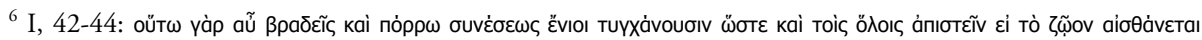

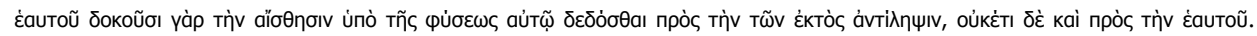
Von der Diskussion darüber, wer diese ßраסєٓ؟ gewesen sein mögen, wird hier völlig abgesehen Vgl. etwa B. Inwood, „Hierocles: Theory and Argument in the Second Century A.D.“, Oxford Studies in Ancient Philosophy 2

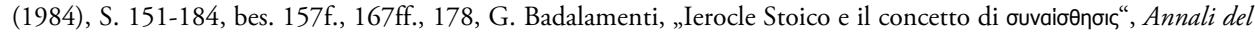
Dipartamento di filosofia (Università di Firenze) 3 (1987), S. 53-97, bes. 61ff., 65ff., 72ff., G. Bastianini/A. A. Long, op. laud., 390ff., A. A. Long, „Hierocles on oikeiôsis and Self-Perception“, in: K. J. Boudouris (Hrsg.), Hellenistic Philosophy, Bd. I, Athens 1993, S. 93-104, bes. 95f. (=A. A. Long, Stoic Studies, Berkeley/LA/London 1996, S. 250-263, bes. 254f.).

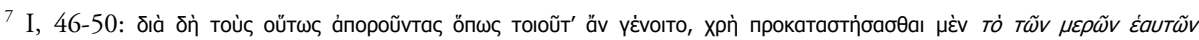

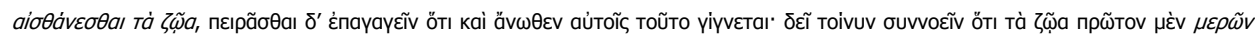

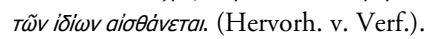


äußeren Wahrnehmung zu verstehen ist, für Hierokles ganz im Gegenteil zum Bereich der Selbstwahrnehmung gehört: weil der Leib ganz entschieden durch den Charakter des Eigenen geprägt ist, zum eigenen Wesen gehört und unmöglich in den Bereich dessen eingeordnet werden darf, was Hierokles als тà ह́ктó bezeichnet. Denn тà ह̇ктóৎ bedeutet demnach all das Wahrgenommene, dem der Grundcharakter des Eigenen fehlt, sei es weil es in einem Milieu in Erscheinung tritt, wo die Grundbestimmung des Selbst völlig ausbleibt (und keine Sphäre des Eigenen vorhanden ist), sei es weil das Wahrgenommene einer vorhandenen Sphäre des Selbst nicht gehört und dieser Sphäre entgegengesetzt wird ${ }^{B}$.

Mit anderen Worten: Hierokles weist darauf hin, dass der Gesamtbereich der Wahrnehmung durch diesen wesentlichen Unterschied geprägt ist. Es gibt so etwas wie Wahrgenommenes, welches als Selbst und als das Eigene empfunden wird. Und es gibt auch Wahrgenommenes, welchem dieser eigentümliche Charakter nicht zukommt. Er geht aber noch einen Schritt weiter. Denn er behauptet, dass jede Wahrnehmung im Grunde genommen immer eine Art Mitempfindung des Eigenen, ein Mindestmaß an Wahrnehmung seiner selbst und seines Wesens miteinschließt, ja wesensmäßig miteinschließen muss. Ihm zufolge gibt es somit überhaupt keine Wahrnehmung, welche in dem oben genannten Sinne in einem Milieu stattfindet, wo die Grundbestimmung des Selbst völlig ausbleibt, und keine Sphäre des Eigenen vorhanden ist, so dass die fragliche Wahrnehmung sich darauf beschränkt, sozusagen völlig freischwebender Inhalte gewahr zu werden, die weder als eigen noch als nicht eigen aufgefasst werden, weil der

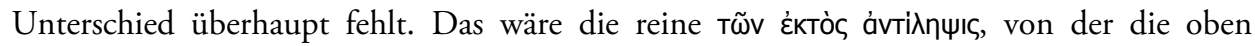
erwähnten ßраठعí sprechen (ohne zu ahnen, wie himmelweit sich eine solche lediglich auf Außendinge gerichtete Wahrnehmung von aller uns bekannten Wahrnehmung unterscheidet). Hierokles hebt hervor, dass die ä̈ønбıৎ nichts Freischwebendes, sondern ihrem Wesen nach

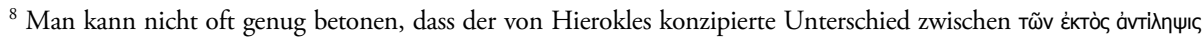

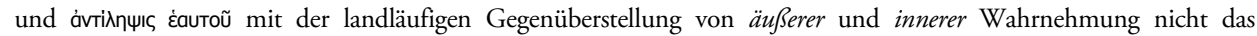
Mindeste zu tun hat. Jede Interpretation, die die Eigentümlichkeit des hierokleischen Ansatzes verkennt und die übliche Gegenüberstellung von äußerer und innerer Wahrnehmung in die Lektüre seiner Fragmente hineinprojiziert,

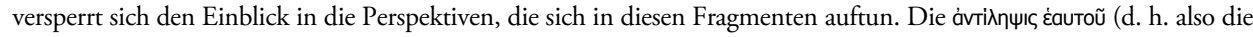
Selbstwahrnehmung im hierokleischen Sinne) ist nicht gleichzusetzen mit der Wahrnehmung der Wahrnehmung (welche dadurch gekennzeichnet ist, dass sie auf das Wahrnehmen selbst gerichtet ist und das Wahrnehmen als solches erfasst). Eben sowenig ist die Selbstwahrnehmung im hierokleischen Sinne mit einer Wahrnehmung des Wahrnehmenden gleichzusetzen, d. h. also mit einer Wahrnehmung, die sozusagen auf die jeweils wahrnehmende Instanz gerichtet ist. Schließlich ist die Selbstwahrnehmung im hierokleischen Sinne auch nicht mit der Wahrnehmung

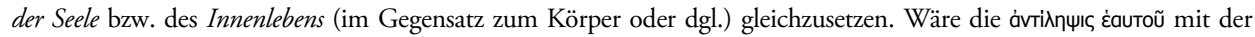
Wahrnehmung der Wahrnehmung, mit der Wahrnehmung des Wahrnehmenden oder mit der Wahrnehmung der Seele oder des Innenlebens gleichzusetzen, dann gehörte alles andere, d. h. also, all das, was von der Wahrnehmung (im Gegensatz zum Wahrgenommenen), von dem Wahrnehmenden selbst oder von der Seele (bzw. dem Innenleben) zu

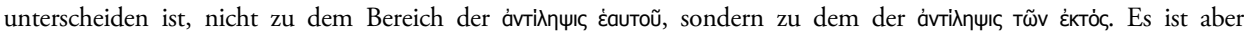

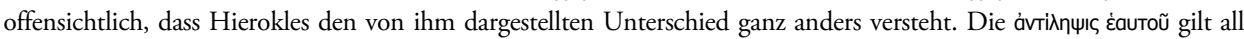
dem, was als eigen wahrgenommen wird, davon abgesehen, wie es beschaffen ist und welche Rolle es als Bestandteil der

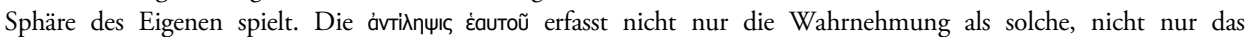
Wahrnehmende, sondern auch ganz „normal“ Wahrgenommenes, sofern das Wahrgenommene als eigen empfunden

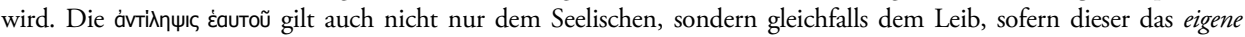

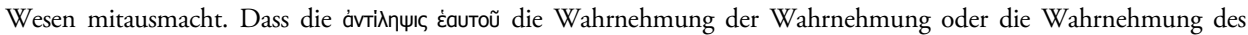
Wahrnehmenden miteinschließt, hängt nicht damit zusammen, dass diese im landläufigen Sinne ,immanent“ sind, sondern vielmehr nur damit, dass die Wahrnehmung als solche oder das Wahrnehmende (genauso wie der Leib) zum Bereich des Eigenen gehören oder Bestandteile des eigenen Wesens sind.
} 
an eine als Mittelpunkt dienende Sphäre des Eigenen, des als Eigen Empfundenen (denn darum geht es!) gebunden ist. Die Rede von einem Mittelpunkt, von der Bindung an einen Mittelpunkt und von der Selbstwahrnehmung als Wahrnehmung des Selbst (des eigenen, als Mittelpunkt dienenden Wesens) soll wohlgemerkt nicht dazu verleiten, an das Verhältnis zwischen der Wahrnehmung und einer Art Träger der Wahrnehmung zu denken. Denn hier geht es nicht um ein solches Verhältnis, sondern vielmehr um eine immanente Gliederung

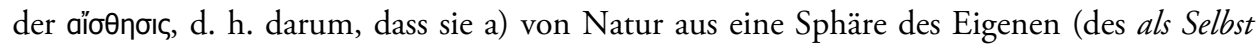
oder als eigen Empfundenen) absteckt, b) im Bereich des Wahrgenommenen den Unterschied zwischen dem Eigenen und dem Nichteigenen ausschlaggebend sein lässt, und

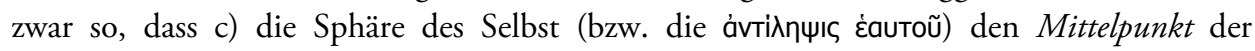
Wahrnehmung und des Wahrgenommenen darstellt.

Nun, was die von Hierokles angeführten Argumente oder Beweise für seine These über die Selbstwahrnehmung anbelangt, so soll das Hauptaugenmerk nicht so sehr auf der Frage liegen, ob die von ihm aufgelisteten Belege über jeden Zweifel erhaben sind und seine These über die Selbstwahrnehmung endgültig bestätigen, sondern eher auf die Frage gerichtet werden, worauf Hierokles eigentlich hindeutet, bzw. was die von ihm besprochenen Begebenheiten letztendlich belegen sollen $-\mathrm{d}$. h., was die fraglichen Begebenheiten (oder vielmehr Hierokles' Schilderung dieser Begebenheiten) über seine Auffassung der Beschaffenheit

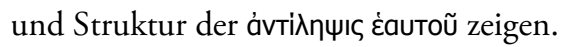

Hierokles weist erstens darauf hin, dass jedes Lebewesen, ob Vogel, Landtier oder Mensch, seine eigenen Glieder und ihre Funktionen wahrnimmt. Beispielsweise ein Vogel nimmt

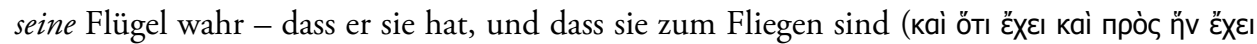
Хpeiav $)^{9}$. Ein Landtier nimmt seine Beine wahr - dass es sie hat, und dass sie zum Gehen sind. Die mit Augen und die mit Ohren ausgestatteten Tiere nehmen ihre Augen und ihre Ohren wahr - dass sie Augen und Ohren haben, und dass die Augen zum Schauen und die Ohren zum Hören sind, etc. ${ }^{10}$ Er hebt also hervor, dass ein Lebewesen, dem Wahrnehmung der eigenen Glieder innewohnt, eines jeden Gliedes so gewahr wird, dass es zugleich das

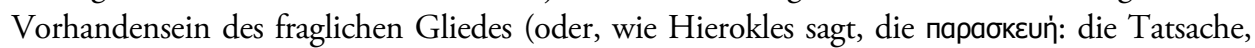

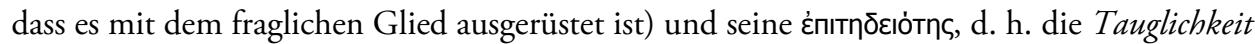
oder Nützlichkeit des fraglichen Gliedes (die Tatsache, dass es zu diesem oder jenem Zweck bzw. zu dieser oder jener Verwendung dienlich ist) wahrnimmt ${ }^{11}$. Des weiteren hebt Hierokles

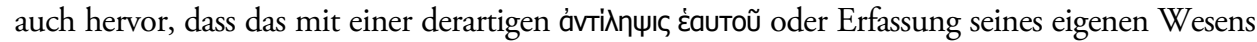
begabte Lebewesen seine verschiedenen Glieder, die verschiedenen Bestandteile seiner парабкєuท่ und ihre verschiedenen Funktionen vollkommen unterscheidet, so dass es etwa den Kopf in eine gewisse Richtung bewegt, um etwas mit den Augen besser zu sehen, oder wiederum in eine andere Richtung, um etwas mit den Ohren besser zu hören, und nicht umgekehrt ${ }^{12}$.

Als zweiten Beleg für seine These führt Hierokles die Tatsache an, dass den Lebewesen die Waffen nicht unbemerkt (man möchte sagen „unwahrgenommen“) bleiben, die ihnen

\footnotetext{
${ }^{9}$ I, 54-55.

${ }^{10}$ I, 51-II, 2.

${ }^{11}$ Vgl. I, 52-53. Vgl. G. Bastianini/A. A. Long, op. laud., z. Stelle, S. 401.

${ }^{12} \mathrm{Vgl}$. I, 55.
} 
die Natur zu Angriff und Verteidigung verliehen hat ${ }^{13}$. Der Stier kennt seine Hörner und ihre Anwendung, die anderen Tiere ihre Hauzähne, ihre Stacheln, das Gift in ihrer Giftdrüse (u. d. h. zugleich den Gebrauch ihrer Hauzähne, ihrer Stacheln, ihres Gifts), etc. ${ }^{14}$

Drittens weist Hierokles darauf hin, dass die Lebewesen ebensowohl der schwachen, empfindlichen oder leichtverletzlichen wie der schwer anzugreifenden, stärkeren und widerstandsfähigen Teile ihrer Körper gewahr werden und dies in ihrem Verhalten zeigen, so dass sie etwa im Fall einer Gefahr ihre empfindlichen Stellen decken und die stärkeren und widerstandsfähigeren der Gefahr aussetzen ${ }^{15}$.

Diese Belege mögen auf den ersten Blick etwas trivial klingen, aber nur solange man ihre tieferliegende Bedeutung und Tragweite und die sehr präzise Charakterisierung der komplexen

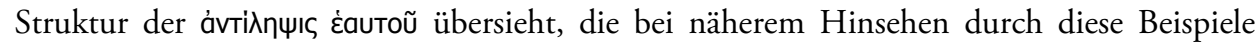
hindurchscheint. Diesbezüglich kann das Allerwesentlichste folgendermaßen formuliert werden:

Betrachtet man das erste der von Hierokles vorgebrachten Argumente, so fällt die strukturierte Mannigfaltigkeit auf, die ihm zufolge der Wahrnehmung eines jeden Gliedes

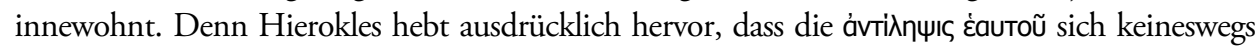
darauf beschränkt, das fragliche Glied einfach wahrzunehmen. Die von ihm beschriebene Wahrnehmung der eigenen Glieder (d.h. die Wahrnehmung eines jeden Gliedes) zeichnet

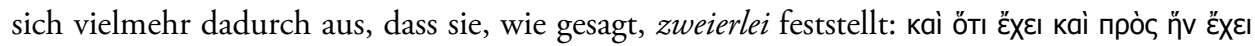

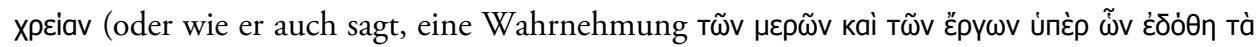
$\mu \varepsilon \dot{p} \eta$ ist $\left.^{16}\right)$. D. h., die Wahrnehmung der eigenen Glieder ist so geartet, dass sie ständig der funktionsbezogenen Beschaffenheit des Gliedes u. d. h. zugleich des Zusammenhangs gewahr wird, der zwischen dem fraglichen Glied und der ihm entsprechenden xpeia (d. h. dem ihm entsprechendem Gebrauch) besteht. Jedes wahrgenommene eigene Glied ist von diesem Zusammenhang nicht zu trennen. Hierokles betont also, dass die Wahrnehmung der eigenen Glieder im Rahmen eines von vornherein auf die xpcia gerichteten Verhaltens stattfindet und alles im Hinblick auf die xpcia (oder, es sei mir erlaubt, mich so auszudrücken, auf den Gebrauch hin) versteht. Die Wahrnehmung der eigenen Glieder stellt also kein schlichtes Erfassen des jeweils Wahrgenommenen dar. Sie ist vielmehr durch ihre irreduzibel komplexe Struktur charakterisiert. Die xpeia ist sozusagen immer mitvernommen, und die Wahrnehmung der eigenen Glieder hat den Charakter eines funktionsbezogenen Sichauskennens - oder

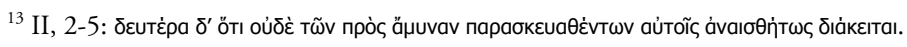

${ }^{14}$ II, 5-18.

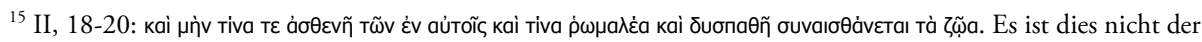
Ort, die verschiedenen Beispiele im Einzelnen zu erörtern, die Hierokles II, 20-III, 19 in diesem Zusammenhang anführt.

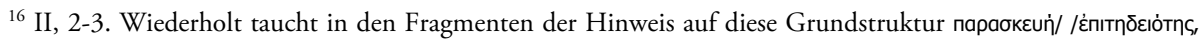

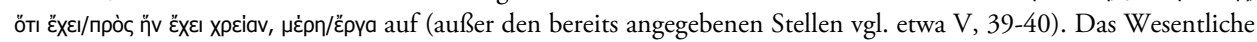
lässt sich folgendermaßen zusammenfassen: 1. Die Sphäre des Eigenen ist sozusagen nicht einfach und einförmig, sondern in verschiedene $\mu \dot{\rho} \rho \eta$ (in verschiedene Glieder, in verschiedene Momente, die zwar nicht miteinander identisch sind, aber insofern zusammengehören, als sie dem eigenen Wesen zugeschrieben und als eigen empfunden werden) gegliedert. 2. Diese erste Gliederung hängt nicht zuletzt auch mit der Tatsache zusammen, dass die verschiedenen Glieder oder Momente der Sphäre des Eigenen mit verschiedenen хрг̃̃a oder ع̌pya verbunden sind. D. h.: Die erste Gliederung hängt mit einer zweiten zusammen, nämlich damit, dass der Bereich der ع̋pya oder der хргі̃ wiederum nicht einfach und einförmig, sondern vielmehr gegliedert ist. 
genauer eines Sichauskennens, welches seinem eigensten Sinne nach voraussetzt, dass das fragliche Lebewesen seiner selbst gewahr wird und sich zu sich selbst so verhält, dass es so

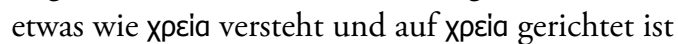

Hier liegt der entscheidende Punkt. Die Selbstwahrnehmung, von der bei Hierokles die Rede ist, zeichnet sich nicht lediglich dadurch aus, dass sie einem ganz besonderen Gegenstand, nämlich der Sphäre des Eigenen (oder als eigen Empfundenen) gilt - als ob sonst kein wesentlicher

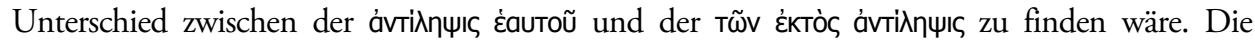
Selbstwahrnehmung im hierokleischen Sinne zeichnet sich vielmehr auch dadurch aus, dass sie eine andersgeartete, andersstrukturierte, von der schlichten Erfassung des Wahrgenommenen (d. h. von der schlichten Erfassung eines vorhandenen Etwas), die für die Wahrnehmung der Außendinge typisch sein soll, toto coelo verschiedene Wahrnehmungsart darstellt.

Dies gilt aber nicht nur für das erste Argument bzw. für die in ihm besprochenen Begebenheiten, sondern auch für das zweite, welches die Waffen betrifft, die die Natur den Lebewesen zu Angriff und Verteidigung verliehen hat. Denn die eigenen Waffen und ihre Wahrnehmung stellen nur einen besonderen Fall des gleichen Sachverhaltes dar. Und Entsprechendes gilt schließlich auch für die schwachen oder leichtverletzlichen und die stärkeren und widerstandsfähigeren Körperteile. Denn auch in diesem Fall ist die von Hierokles

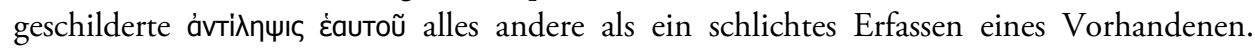
Seiner schwachen oder leichtverletzlichen und seiner stärkeren und widerstandsfähigeren Körperteile wird ein Lebewesen nämlich so gewahr, dass es sie eben deswegen als schwach oder leichtverletzlich, stark etc., empfindet, weil es sie mit der Vorstellung eines möglichen Angriffes u. dgl. in Verbindung setzt. Auch in diesem Fall ist die Wahrnehmung demnach so geartet, dass das Wahrgenommene mit einer möglichen xpsia im Zusammenhang steht, und zwar so, dass dieser Zusammenhang mit einer möglichen xpeia stets mitwahrgenommen wird ${ }^{17}$. Auch in diesem Fall weist die Selbstwahrnehmung also den Charakter eines

${ }^{17}$ Das Wort xpeia wird hier wohlgemerkt im weiteren Sinne verstanden. Xpeia bietet eine große Fülle von Bedeutungen. Die einen variieren und modifizieren die Grundbedeutung egestas (so z. B. Bedürfnis, Notwendigkeit, Mangel, Entbehrung, Not, Verlangen, Erfordernis, Aufgabe), die anderen die Grundbedeutung usus (Gebrauch, Benutzung und Anwendung, Nutzen, Vorteil, Zweck, Genuss, das, was man treibt oder betreibt, Umgang, praktisches Verhalten, etc.) Zum Bedeutungsfeld des Wortes s. z. B. G. Redard, Recherches sur XPH, XPHIOAI. Étude sémantique, Paris 1953, bes. S. 80ff., W. Spoerri, Späthellenistische Berichte über Welt, Kultur und Götter, Basel 1959, S. 144ff., K. Thraede, „Das Lob des Erfinders. Bemerkungen zur Analyse der Heuremata-Kataloge“, Rheinisches Museum NF 105 (1962), S. 158-186, hier 167ff., H.-R. Hollerbach, Die Bedeutung des Wortes xpeia, Diss. Köln 1964. Es gilt vor allen Dingen das Wort nicht zu einseitig zu verstehen, als ob das hier in Frage Stehende immer eine Art Tätigkeit des betreffenden Lebewesens und zwar eine positive, erstrebenswerte, nützliche Tätigkeit sein müsste. Auf den ersten Blick scheint Hierokles nur Derartiges zu meinen. Bei näherem Hinsehen stellt sich aber heraus, dass die von ihm hervorgehobene phänomenale

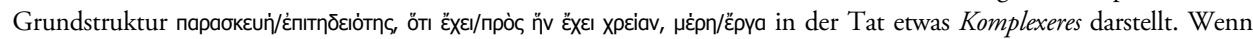
ein Lebewesen beispielsweise der schwachen, empfindlichen oder leichtverletzlichen Teile seines Körpers gewahr wird, so hängt dies natürlich mit einem Abwehrverhalten, d. h. also mit einer möglichen Tätigkeit des betreffenden Lebewesens zusammen. Dieses Abwehrverhalten ist aber seinerseits auf einen möglichen Angriff und auf die daraus resultierenden möglichen Schäden für das betreffende Lebewesen bezogen, die es zu vermeiden sucht. Daraus geht zweierlei hervor. 1. Bei der Wahrnehmung der eigenen Glieder wird nicht unbedingt nur eine mögliche Tätigkeit des betreffenden Lebewesens (eine mögliche Betätigung seiner Glieder) wahrgenommen, sondern auch das, was diesen Gliedern (und somit dem fraglichen Lebewesen) widerfahren, zustoßen kann, und d. h. zugleich das daraus resultierende Befinden des fraglichen Lebewesens. In dieser Beziehung stellt die Wahrnehmung der schwachen, empfindlichen oder leichtverletzlichen Teile des eigenen Körpers eigentlich keinen Sonderfall dar. Denn auch in den anderen Fällen verhält es sich so, dass die mitwahrgenommene mögliche Tätigkeit des betreffenden Lebewesens zu einem Resultat, nämlich zu 
funktionsbezogenen Sichauskennens auf - oder genauer den Charakter eines Sichauskennens, welches seinem Sinne nach zur Voraussetzung hat, dass das fragliche Lebewesen seiner selbst gewahr wird und sich zu sich selbst so verhält, dass es so etwas wie xpeia versteht und auf xpsia gerichtet ist.

Hier gilt es aber noch einen wichtigen Punkt hervorzuheben, der aus dem Ausgeführten gleichfalls hervorgeht. Es wurde nämlich darauf hingewiesen, dass jede in den soeben besprochenen Phänomenen in Frage stehende Wahrnehmung - die Wahrnehmung der eigenen Glieder (oder vielmehr die eines jeden Gliedes), die Wahrnehmung der eigenen Waffen, die Wahrnehmung eines schwächeren und die eines widerstandsfähigeren Teiles, etc. - irreduzibel komplex ist und eine Mannigfaltigkeit von verschiedenen Momenten umfasst. Man darf aber nicht vergessen, dass diese verschiedenen Momente - oder sagen wir so, diese verschiedenen

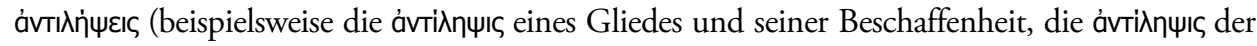
ihm entsprechenden xpsia, usw.) kein bloßes Aggregat, kein bloßes Nebeneinander bilden. Man neigt zwar dazu, sich die verschiedenen Wahrnehmungsmomente als eine Art von nebeneinanderliegenden Mosaikstücken vorzustellen, die lediglich aneinandergereiht werden. Es zeigt sich aber, dass dies hinsichtlich der verschiedenen Momente jeder von Hierokles

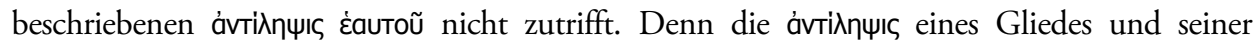

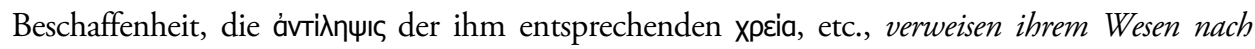
aufeinander. Es handelt sich sozusagen um verkettete, aufs Innigste miteinander verquickte „Wahrnehmungsinhalte", die durch das Band eines sinnvollen Zusammenhanges verbunden sind. Und eben dies - nämlich, dass sie die innere Struktur eines solchen sinnvollen Zusammenhanges

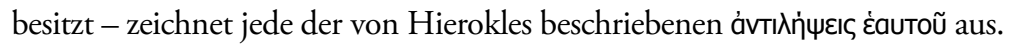

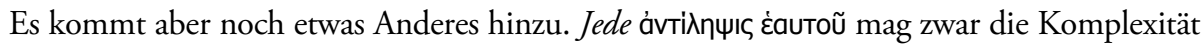
eines sinnvollen Zusammenhanges und keineswegs den Charakter eines bloßen Aggregates

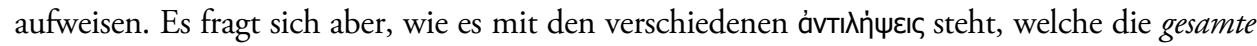
Sphäre der Selbstwahrnehmung im hierokleischen Sinne zusammensetzen. Hierokles weist

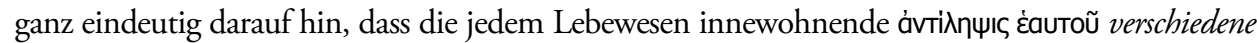
Momente, unter anderen auch diejenigen umfasst, die er ausdrücklich nennt, nämlich die Wahrnehmung der verschiedenen Glieder, sowie die der eigenen Waffen und die der schwächeren und stärkeren Teile, etc. Diese verschiedenen Momente der Selbstwahrnehmung

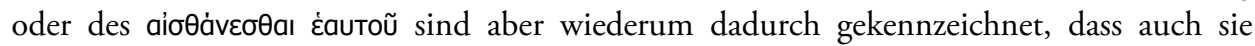

einer positiven Entwicklung seines Zustandes führen soll, und zwar dergestalt, dass nicht zuletzt auch dieser positive Zustand, zu dem das Lebewesen tendiert und welchen die fragliche mögliche Tätigkeit herbeiführen soll, bei der Wahrnehmung des eigenen Wesens mitwahrgenommen wird. 2. Es stellt sich aber auch heraus, dass bei der Wahrnehmung der eigenen Glieder nicht nur etwas Positives, zu dem das fragliche Lebewesen tendiert, sondern auch etwas Negatives, Schadhaftes mitwahrgenommen werden kann, das es zu vermeiden gilt. In summa, der Sache nach umfasst das zweite Moment der von Hierokles hervorgehobenen Struktur, nämlich das Moment der mitwahrgenommenen xpeia oder des mitwahrgenommenen हैppov nicht nur a) mögliche Tätigkeiten, sondern auch b) mögliches Betroffenwerden, mögliche Wechselfälle und mögliche Zustände des eigenen Wesens, ja nicht nur c) Positives oder Erstrebenswertes, sondern auch d) Negatives, zu Vermeidendes. Die von Hierokles hervorgehobene Wahrnehmung des eigenen Wesens ist so beschaffen, dass sie sich stets zu diesem komplexen Bereich des Möglichen verhält. „Xpria“ (aber auch ,हैpyov") sind besonders geeignet, die hier in Frage stehende komplexe Konstellation verschiedenartiger Funktionen zu bezeichnen, weil ihr sehr weitläufiges, eine große Fülle von Bedeutungen umfassendes Bedeutungsfeld den weiteren Schritt zu einem formalen, all die genannten Aspekte auf einen gemeinsamen Nenner bringenden Begriff gleichsam präfiguriert. 


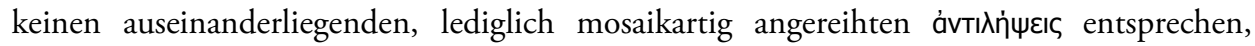
sondern ganz im Gegenteil durch einen sinnvollen Gesamtzusammenhang miteinander verbunden sind. Die Wahrnehmung der verschiedenen Elemente, die zur Sphäre des eigenen Wesens so gehören, dass das Wahrnehmende dessen inne wird, dass es sie besitzt (öтı ह̌’દı), verbindet diese verschiedenen Elemente als das, was das eigene Wesen (das Selbst) ausmacht und bestimmt. Es zeigt sich aber, dass all diese Elemente durch ihre funktionsbezogene Beschaffenheit gekennzeichnet sind, d. h. von vornherein прò xpвiav oder sozusagen auf Funktionen des Selbst hin verstanden werden und mit einer Gesamtheit verschiedener Funktionen oder verschiedener Möglichkeiten im Bereich der xpsia aufs Innigste zusammenhängen. Diese verschiedenen Funktionen oder differenzierten Möglichkeiten des Selbst sind ihrerseits so geartet, dass auch sie keinem bloßen Aggregat lediglich aneinandergereihter ávтı $\lambda \dot{\psi} \psi \varepsilon ı$ und lediglich aneinandergereihter Percepta entsprechen, sondern vielmehr durch einen sinnvollen Zusammenhang verbunden sind und eine Art Gesamtheit möglicher miteinander zusammenhängender xp乏iaı darstellen, die das Wahrnehmende versteht, in der es sich stets bewegt und zu der es sich ständig verhält.

Damit bekommt man einen ersten Überblick über die Totalität der von Hierokles beschriebenen Sphäre des Eigenen (d. h., wenn man sich so ausdrücken darf, über den

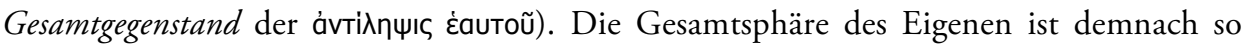
geartet, dass sie sowohl die verschiedenen miteinander zusammenhängenden Momente des eigenen Wesens (sozusagen ă ह̌xદı) als auch die verschiedenen miteinander zusammenhängenden хргі̃a im weitesten Sinne umfasst, die für das betreffende Wesen in Frage kommen können und zwar dergestalt, dass diese beiden Bereiche nicht nach Art eines Aggregats lediglich aneinandergereiht sind, sondern vielmehr ihrem Wesen nach aufeinander verweisen und durch ein Netz sinnvoller Bezüge aufs Innigste zusammenhängen und unzertrennlich verbunden sind.

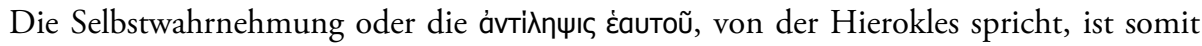
nichts weniger als etwas Einfaches oder sozusagen Bestimmungsarmes. Ganz im Gegenteil: Das Ausgeführte zeigt die Weite und Komplexität der Sphäre des Eigenen, so wie sie von Hierokles beschrieben wird - dass es sich um eine ziemlich komplexe, mehrschichtige und

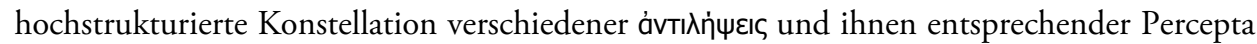
handelt, die gemeinsam dafür verantwortlich sind, dass es eine Vorstellung des eigenen Wesens überhaupt gibt, und dass das wahrgenommene eigene Wesen mit einer konkreten Beschaffenheit versehen ist, nach der sich sein Verhalten zu sich selbst richtet.

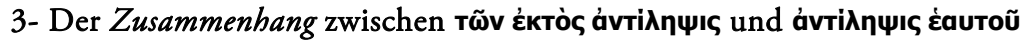

Es gilt aber jetzt einen Schritt weiter zu gehen und Hierokles' viertes Argument bzw. das vierte Moment der von ihm herangezogenen phänomenalen Tatsachen zu betrachten, die seine These über die Selbstwahrnehmung belegen sollen. Hierokles beruft sich nämlich auf die Tatsache, dass die Lebewesen auch die Stärken und Schwächen anderer Lebewesen wahrnehmen und ihre Kenntnis derselben in ihrer Kampfweise verraten. Hinzu kommt, dass die Lebewesen auch imstande sind, die anderen Lebewesen, die für sie eine Gefahr bedeuten, diejenigen, von denen sie nichts zu fürchten haben und auch die, welche sie als 
Verbündete betrachten und nutzen können, zu unterscheiden, und zwar so, dass sie diese eigentümliche Wahrnehmungsfähigkeit in ihrem Verhalten ständig verraten ${ }^{18}$.

Nun, auf den ersten Blick mag es sogar befremden, dass diese Tatsache als Beleg für die

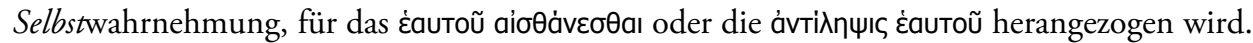
Denn es handelt sich ganz offensichtlich um $A u ß e n d i n g e$, die eben dadurch gekennzeichnet sind, dass sie fremd sind und außerhalb der Sphäre des Eigenen (d. h. also ausgeprochen غ̇kтós) liegen. So scheint es sich in der Tat zu verhalten, und es fehlt auch nicht an Interpreten, die dieses vierte Argument als einen Argumentationsfehler, da es im Grunde genommen nichts zur Sache tut, brandmarken ${ }^{19}$. Die angebliche Evidenz, auf die sich solche Interpreten berufen, erweist sich jedoch als trügerisch. Und eine sich auf diese „Evidenz“ verlassende Interpretation versperrt sich durch ihren zu engen Blickwinkel das Verständnis des fraglichen Phänomenzusammenhangs und ist unausweichlich dazu verurteilt, das Wesentliche zu verfehlen.

Denn gerade dies, nämlich dass Hierokles sich im Rahmen einer Erörterung der

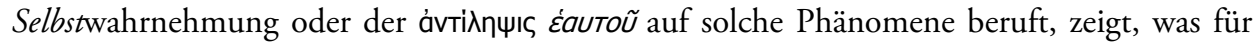
einen Zusammenhang er eigentlich im Auge hat, was er genaugenommen unter Selbstwahrnehmung versteht und nicht zuletzt auch, was er über ihre entscheidende Rolle geltend machen will.

Was haben die fraglichen Phänomene aber mit Selbstwahrnehmung (d.h. mit der Wahrnehmung des Eigenen) zu tun?

Es fällt zunächst einmal Folgendes auf: Auch die im vierten Argument besprochenen Wahrnehmungen sind so geartet, dass sie sich auf ein schlichtes Erfassen eines vorhandenen Etwas nicht reduzieren lassen. Die Schwächen und Stärken der anderen Lebewesen, dass sie eine Gefahr bilden oder nicht, etc. - all das stellt eine Art von Beschaffenheit dar, die ihrem Wesen nach auf eine xpeia im weiteren Sinne relativ ist. D. h., auch in diesem Fall verhält es sich so, dass das Wahrgenommene mit der Projektion eines Gebrauchs, einer Anwendung, kurz, einer Funktion zusammenhängt, und zwar dergestalt, dass 1. es im Grunde genommen ohne eine derartige Projektion nicht möglich wäre und 2. die ihm innewohnende Bestimmung von dem Bezug auf die fragliche Funktion abhängt. Aber hier liegt allerdings zugleich auch der springende Punkt. Denn die Funktion, auf welche die Schwächen und die Stärken anderer Tiere oder die Frage relativ sind, ob die anderen Lebewesen eine Gefahr bedeuten oder ganz im Gegenteil harmlos, etc. sind, betrifft nicht nur die anderen Lebewesen, sondern auch, ja hauptsächlich das eigene Wesen des Wahrnehmenden und seine xpeia. Denn die Schwächen und Stärken der anderen Lebewesen, ihre feindliche, neutrale oder wohlwollende „Gesinnung“ sind für das eigene Wesen in seinem Umgang mit den anderen Lebewesen von entscheidender Bedeutung. Und darum geht es. Es handelt sich zwar um Eigenschaften der anderen Lebewesen (und nicht des eigenen Wesens), diese Eigenschaften der anderen Lebewesen zeichnen sich aber dadurch aus, dass sie wesensmäßig funktionsbezogen sind, und dass der terminus ad quem der ihnen innewohnenden funktionsbezogenen Verweisung die xpsia des Selbst oder Funktionen des Selbst sind. Kurz: Die anderen Lebewesen werden auf Funktionen des Selbst

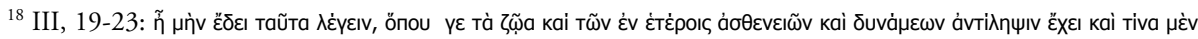

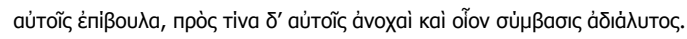

${ }^{19}$ Vgl. etwa H. von Arnim (Hrsg.), Hierokles, Ethische Elementarlehre (Papyrus 9780), op. laud., S. XXI f. 
hin verstanden. Die Wahrnehmung derartiger Außendinge (und dass es sich um Außendinge handelt, duldet in der Tat keinen Zweifel) ist so beschaffen, dass sie von einer Mitwahrnehmung oder Mitempfindung des eigenen Wesens begleitet, ja so begleitet wird, dass diese Mitwahrnehmung des eigenen Wesens (nota bene: mit all dem, was dazu gehört: $\mathrm{d}$. h. also nicht nur die Tatsache, dass das eigene Wesen vorhanden, sondern im Grunde genommen auch, dass es so oder so beschaffen und auf eine so oder so bestimmte Sphäre möglicher Xpeĩa gerichtet ist) den Tenor der äußeren Wahrnehmung, die Bestimmung des Außendinges selbst mitbeeinflusst und für die Art und Weise maßgebend ist, wie dieses erscheint, als was es erscheint, was an ihm zählt und wahrgenommen wird, etc.

Und das ist allem Anschein nach der Grund, warum Hierokles diese Art von

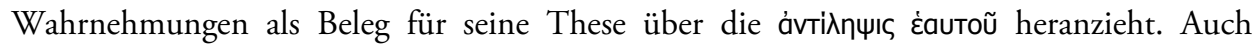
Außendinge nimmt ein Lebewesen dergestalt wahr, dass der äußeren Wahrnehmung (d. h. der Wahrnehmung fremder Dinge) eine Art Rückverweis oder Rückbezug auf sein eigenes Wesen (d. h. also auf die soeben umrissene Sphäre des Eigenen) innewohnt. Oder, wie man auch sagen kann, in den von Hierokles genannten Beispielen nimmt ein Lebewesen die anderen Wesen gleichsam um sich selbst zentriert wahr.

Ein Blick auf ein anderes, von Stobaios überliefertes und im übrigen sehr berühmtes Fragment des Hierokles kann uns zur Verdeutlichung des hier in Frage stehenden phänomenalen Zusammenhangs verhelfen ${ }^{20}$. Der Kontext scheint zwar ein ganz anderer zu sein, bei genauerem Hinsehen stellt sich indessen heraus, dass es in beiden Fällen doch um die gleiche Grundstruktur geht.

Das fragliche Fragment bespricht eine Art abnehmender Stufenfolge der Anhänglichkeit (der Zuneigung, des Interesses oder der Anteilnahme), die durch ein Gleichnis illustriert wird: „Jeder von uns ist gleichsam völlig eingeschlossen durch viele Kreise, davon sind einige kleiner, einige größer, wobei die letzteren die ersteren einschließen je nach ihrem ungleichen Verhältnis und ihren verschiedenen Lagebeziehungen zueinander. Der erste und einem am nächsten liegende Kreis ist der, der ein Mensch gleichsam um einen Mittelpunkt (кह่vтроv), nämlich seine Seele (סı́avoıa) herum gebildet hat. In diesem ist der Körper enthalten, und all das, was man sich dem Körper zuliebe eignet. Denn dieser ist der kleinste Kreis und er berührt beinahe den Mittelpunkt selbst. Als zweiter kommt ein von dem Mittelpunkt weiter entfernter Kreis, der aber den ersten einschließt; diesem Kreis gehören Eltern, Geschwister, Ehefrau, und Kinder. Der dritte ist der Kreis, in dem Onkel, Tanten, Großväter und Mütter, Neffen, Nichten und Vettern zu finden sind. Der nächste ist jener Kreis, der andere Verwandte umfasst; auf ihn folgt der Kreis der Mitbürger, die dem gleichen Demos, und dann der Kreis derer, die dem gleichen Stamm ( $\varphi$ Ùn்) angehören; dann der Kreis der anderen, die aus der selben Stadt stammen, schließlich auch der Kreis der Menschen aus

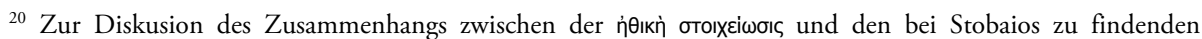
Fragmenten vgl. etwa K. Praechter, Hierokles der Stoiker, Leipzig 1901, H. von Arnim (Hrsg.), Hierokles, Ethische Elementarlehre (Papyrus 9780), op. laud., S. IXff., Ders., „Zum Platoniker Gaios“, Hermes 51 (1916), S. 510-529, bes. 519, F. Ueberweg/K. Praechter, Grundriß der Geschichte der Philosophie, Bd. 1, Philosophie des Altertums, Basel $1957^{14}$, S. 499, R. Philippson, „Hierokles der Stoiker“, Rheinisches Museum für Philologie 72 (1933), S. $97-$

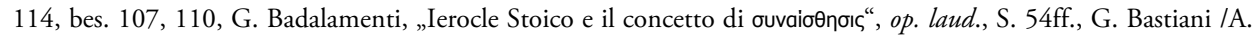
A. Long, op. laud., S. $281 \mathrm{ff} .$, A. A. Long, „Notes on Hierocles Stoicus apud Stobaeum“, in: M. S. Funghi (Hrsg.), OAOI $\triangle I Z H I I O \Sigma:$ Le Vie della Ricerca. Studi in onore di Francesco Adorno, Firenze 1996, S. 299-309. 
Nachbarstädten und der Kreis der Volksgenossen. Der äußerste und größte Kreis, der alle übrigen einschließt, ist der Kreis des ganzen Menschengeschlechts. " ${ }^{21}$

Nach Hierokles ist jeder Einzelne gleichsam der Mittelpunkt dieser Reihe immer weiter ausgreifender konzentrischer Kreise, die von dem eigenen Leib, über die engsten Verwandten, die weitere Familie, die Nachbarschaft, die Stadtgemeinde und die Volksgemeinde bis zu der gesamten Menschheit reicht. Die von Hierokles konzipierte Reihe konzentrischer Kreise soll die unterschiedliche Art und Weise illustrieren, wie diese verschiedenen Wesen Zuneigung und Zugehörigkeitsgefühl erwecken, für wichtig gehalten werden, etc. Wichtig ist hier vor allem, dass die Sphäre des Eigenen den Mittelpunkt bildet. Dies bedeutet zunächst einmal, dass diese Sphäre im wahrsten Sinne des Wortes im Brennpunkt des Interesses steht, so dass es im ganzen Bereich des Wahrgenommenen hauptsächlich um dieses Wesen - nämlich um das Eigene oder um das Selbst - geht. Aber es bedeutet zugleich, dass alles Andere eben in dem Maße auch ins Gewicht fällt, Zuneigung erweckt, etc., wie es dem eigenen Wesen nahe ist (mit ihm zusammenhängt, etc.) oder ganz im Gegenteil fern bleibt. Das ist der Sinn der durch die immer weiter ausgreifenden konzentrischen Kreise illustrierten abnehmenden Stufenfolge, welche zugleich die allmählich zunehmende Ferne zur Sphäre des Selbst und die entsprechend fallende Intensität des Interesses veranschaulichen soll.

Hier darf man sich aber nicht „an den Buchstaben klammern“. Es besteht nämlich die Gefahr, das hierokleische Gleichnis so zu verstehen, dass es ganz eigentümliche und regionale, nur den Bereich der zwischenmenschlichen Beziehungen betreffenden Sachverhalte ausdrückt. Eine derartige Interpretation bleibt aber an der Oberfläche. Denn das Entscheidende besteht gerade darin, dass das Gleichnis der konzentrischen Kreise ganz im Gegenteil eine durch dieses konkrete Beispiel hindurchscheinende formale Grundstruktur hervorhebt, welche weit über diesen engen Bereich ihre Geltung bewahrt. Ja, schon hinsichtlich der zwischenmenschlichen Beziehungen besteht das Entscheidende nicht so sehr in der von Hierokles beschriebenen konkreten Rollenverteilung (als ob diese ein für allemal fest stünde und in allen Fällen gleich sein müsste), sondern eher in dem formalen Gefüge der verschiedenen, konzentrisch aufeinander folgenden Kreise, deren konkrete „Besetzung“ freilich in weitem Ausmaß variieren kann. Es ist darüber hinaus auch ohne weiteres klar, dass die hier in Frage stehende Struktur nicht nur für die Variation des Interesses im Bereich der zwischenmenschlichen Beziehungen, sondern auch für die Variation des Interesses in Bezug auf andere Lebewesen oder auch auf Sachen gilt. Die von Hierokles dargestellten konzentrischen Kreise sind allerdings auch insofern einseitig, als sie beispielsweise nur die Variation des positiven Interesses berücksichtigen und die eben so wichtige Variation (die analog abnehmende

\footnotetext{
${ }^{21}$ Ioannis Stobaei anthologium, hrsg. von C. Wachsmuth/O. Hense, Berlin 1884-1912, IV.27.23 (IV, S. 671f.):

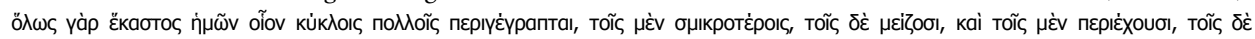

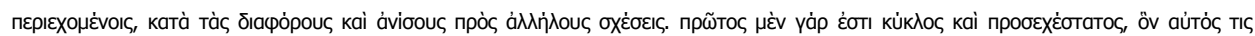

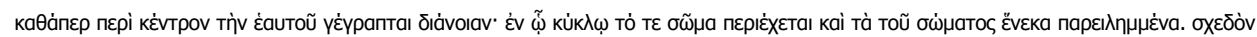

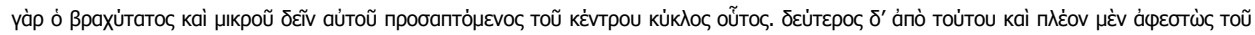

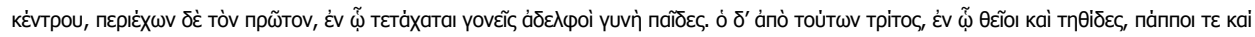

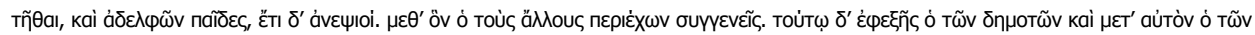

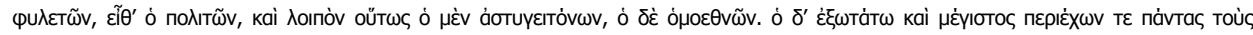

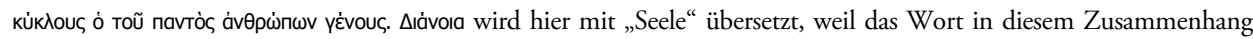
kein spezifisches Vermögen, sondern vielmehr das zu bezeichnen scheint, was dem Körper entgegengesetzt wird.
} 
Stufenfolge) des Antagonismus außer Acht lassen. All dies mag wohl auf den spezifischen Kontext des Gleichnisses zurückzuführen sein, denn es gibt andere Texte des Hierokles, die all dem Rechnung tragen.

Dies braucht man aber hier nicht näher zu erörtern. Denn das Wesentliche ist jedenfalls das Grundphänomen der Zentrierung, d. h. die durch dieses Gleichnis deutlich veranschaulichte Tatsache, dass das ganze Feld des Wahrgenommenen in dem Selbst (in der Sphäre des

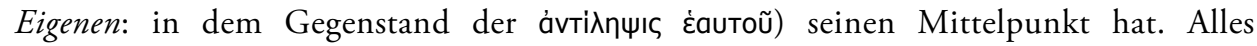
Wahrgenommene ist auf einen Mittelpunkt zentriert - und das heißt jetzt ganz speziell: tà غ́ктós, die Gegenstände der äußeren Wahrnehmung im hierokleischen Sinne, laufen auf

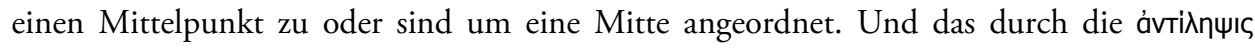
غ̇autoũ wahrgenommene eigene Wesen des Wahrnehmenden ist es, das den Mittelpunkt dieses zentrierten Feldes besetzt und in aller und jeder Wahrnehmung diese Rolle spielt.

Es gilt, dieses Grundphänomen etwas näher ins Auge zu fassen, indem man von den Unterschieden absieht, sich auf den gemeinsamen Nenner konzentriert und die Art und Weise herausarbeitet, wie sowohl die Wahrnehmungen, auf die sich das vierte Argument beruft, als auch das Gleichnis der konzentrischen Kreise im Grunde genommen die gleiche formale Struktur widerspiegeln und Spielarten ein und desselben Grundphänomens darstellen ${ }^{22}$.

In dem bei Stobaios zu findenden Gleichnis sind zwar zwei Aspekte ausschlaggebend,

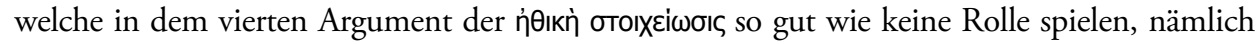
die zunehmende Entfernung vom Mittelpunkt und die entsprechend fallende Intensität des Zugehörigkeitsgefühls, des Interesses oder der Anteilnahme. Es zeigt sich aber, dass das Gleichnis der konzentrischen Kreise von „Außendingen“ spricht, die keineswegs durch ein schlichtes Erfassen ihres bloßen Vorhandenseins, sondern ganz im Gegenteil so wahrgenommen werden, dass ihnen eine Art Rückverweis oder Rückbezug auf das eigene Wesen des Wahrnehmenden (u. d. h. wohlgemerkt auf die Sphäre seiner xpeia im weitesten Sinne) innewohnt. Dieser Rückbezug oder Rückverweis ist es, der über den Grad des Interesses entscheidet, welcher dem jeweils Wahrgenommenen zukommt und diesem somit seinen Platz innerhalb der von Hierokles beschriebenen konzentrischen Kreise zuweist. Auch hier ist also die Art und Weise, wie ein Außending wahrgenommen wird, durch die

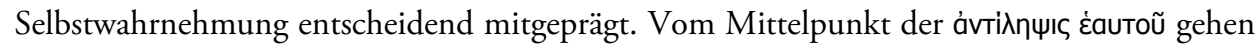
Bezüge und Linien - und diese Bezüge und Linien sind es, die das ganze Gefüge der fraglichen konzentrischen Kreise ermöglichen und gestalten.

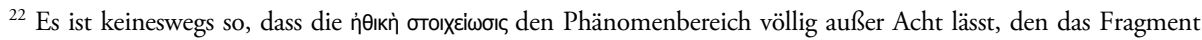

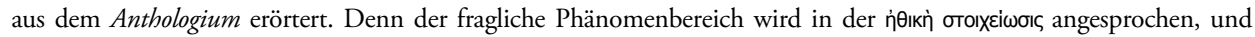

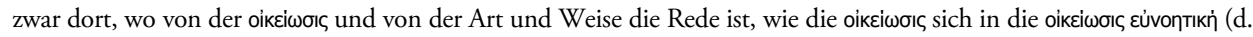

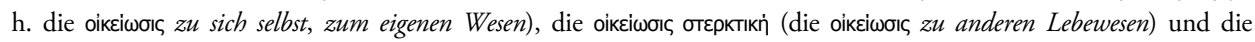

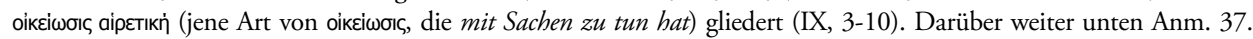

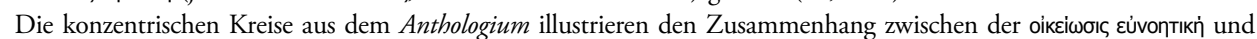

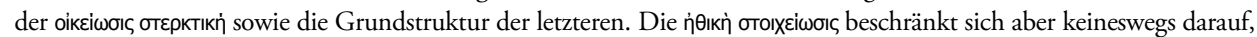
den fraglichen Phänomenbereich flüchtig zu erwähnen. Denn ein weitgehend verlorener Teil des Textes (Kolumne IX

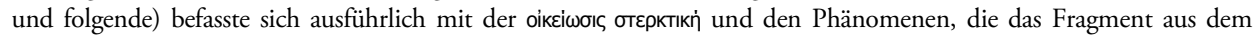
Anthologium erörtert. Der Zusammenhang zwischen der Struktur der Wahrnehmung und der durch die

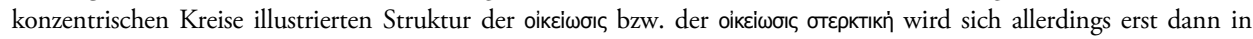

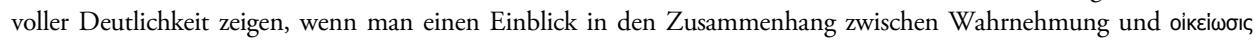
gewonnen hat, von dem weiter unten noch die Rede sein wird. 
Betrachtet man nun die Wahrnehmungen, auf die sich das 4. Argument der ウंӨıкn்

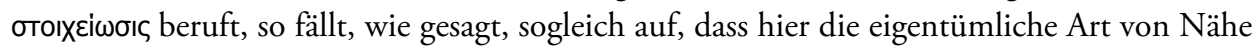
und Distanz keine Rolle spielt, die für die konzentrischen Kreise des variierenden Interesses ausschlaggebend ist. Dies verhindert aber keineswegs, dass auch in diesem Fall von einer Zentrierung und von einem Mittelpunkt die Rede sein darf - und zwar dergestalt, dass das hier in Frage stehende Zentrierungsphänomen im Grunde genommen das gleiche ist. Denn auch hier, genau so wie im Fall der konzentrischen Kreise, verhält es sich erstens so, dass die

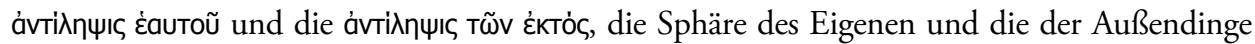
miteinander zusammenbestehen, so dass das eigene Wesen bei der Wahrnehmung von Außendingen mitvernommen wird. Hierokles betont immer wieder die ununterbrochene Kontinuität der Selbstwahrnehmung, die es mit sich bringt, dass es überhaupt keine äußere Wahrnehmung gibt, die von einer Selbstwahrnehmung nicht begleitet werde ${ }^{23}$. Seine diesbezüglichen Argumente können sogar auf eine falsche Fährte führen. Er hebt nämlich

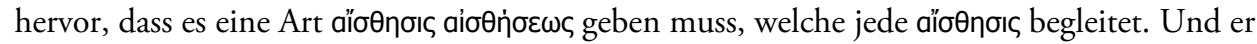

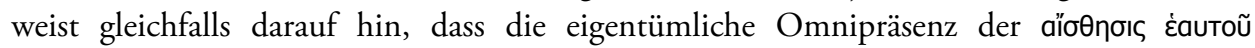
schließlich mit der Tatsache zusammenhängt, dass ein Lebewesen beispielsweise das Weiße, das Süße oder das Warme nicht wahrnehmen kann, ohne zugleich sein eigenes Weiß- Süßund Warmwerden (nämlich in der Vorstellung) wahrzunehmen ${ }^{24}$ : Ja er spricht sogar von

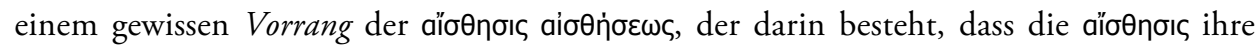
Tätigkeit in erster Linie auf sich selbst erstreckt und sich selbst erfasst, bevor sie irgendein anderes Ding wahrnimmt ${ }^{25}$. Dies alles kann dazu verleiten, zu meinen, dass er innerhalb der

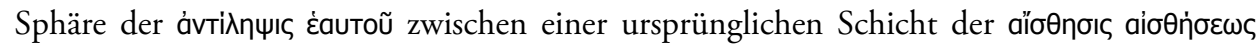

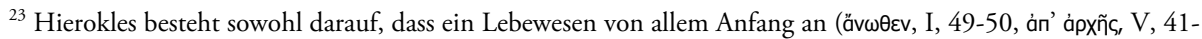

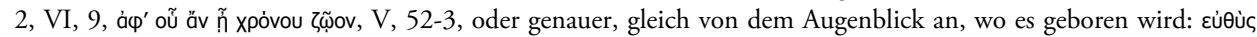

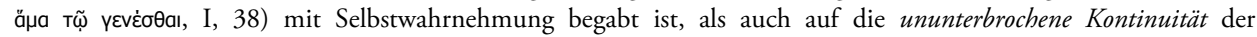

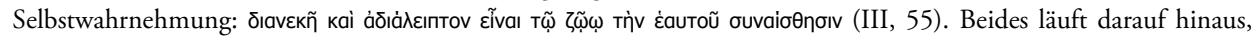

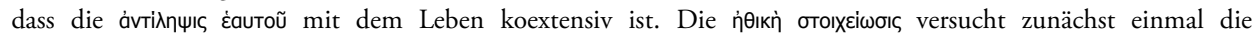
ununterbrochene Kontinuität der Selbstwahrnehmung anhand verschiedener Argumente ausführlich darzulegen (III, 54- V, 41). Und dann wird auch die These, dass die Selbstwahrnehmung bis zur Geburt zurückreicht, mit verschiedenen Argumenten untermauert (V, 40-VI, 27). Hier muss man aber auf eine ins Detail gehende Erörterung der von Hierokles dargelegten Argumentation verzichten und sich darauf beschränken, einigen Punkten besondere Aufmerksamkeit zu schenken. Hinsichtlich der ununterbrochenen Kontinuität der Selbstwahrnehmung gilt es vor allen Dingen einen Aspekt hervorzuheben, der für das Verständnis des hier in Frage stehenden Begriffs von Wahrnehmung ausschlaggebend ist. Hierokles weist nämlich darauf hin, dass selbst im tiefsten Schlaf, der einer

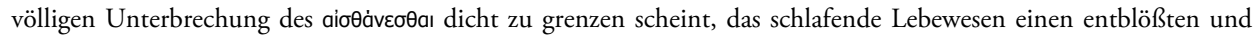
darum verfrorenen Teil seines Körpers wieder zudeckt oder eine Wundstelle vor Quetschung oder Stoß schützt und

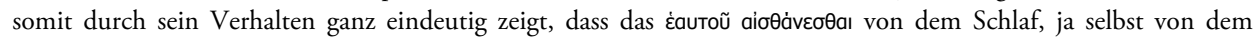
tiefsten Schlaf nicht unterbrochen wird. Vgl. IV, 53-V, 30.

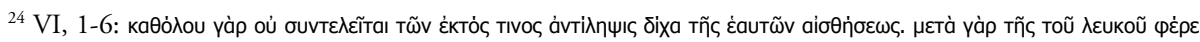

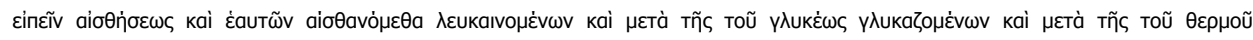

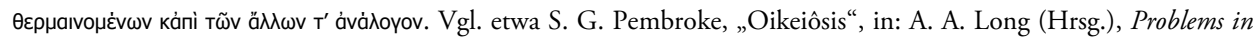
Stoicism, London/Atlantic Highlands (N.J.) 1971, 114-149, hier 118, und B. Inwood, „Hierocles: Theory and Argument in the Second Century A.D.“, Oxford Studies in Ancient Philosophy 2 (1984), S. 151-184, bes. 166, G.

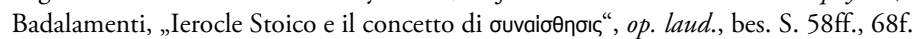

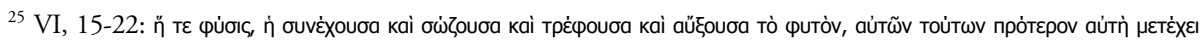

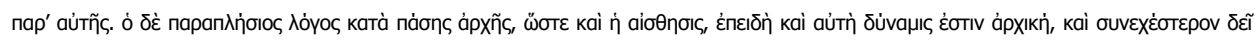

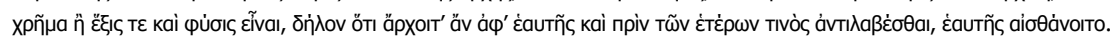




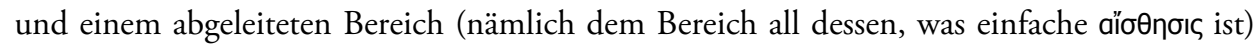
unterscheidet. Das ist aber nicht der Fall - ihm ist eigentlich nur daran gelegen, die besagte Kontinuität und Omnipräsenz der Selbstwahrnehmung geltend zu machen. Und all diese Argumente dienen lediglich dazu, diese These zu untermauern, so dass sie dann keine weitere Rolle spielen, und es die ganze ávтi內nчıৎ દ̇auтoũ in dem oben besprochenen Sinne ist, die Hierokles zufolge bei der Wahrnehmung von Außendingen ständig mitvernommen oder mitempfunden wird $^{26}$.

Das ist aber nur der erste Punkt. Noch schwerwiegender ist der zweite, nämlich dass die alle äußere Wahrnehmung unentwegt begleitende Selbstwahrnehmung sich nicht darauf beschränkt, eine Art basso continuo für die äußere Wahrnehmung zu bilden. Sie zeichnet sich vielmehr dadurch aus, dass sie die äußere Wahrnehmung gleichsam in ihre Einflußsphäre zieht und sich selbst unterordnet. Dies tut sie, indem sie sich sozusagen in den Bereich der äußeren Wahrnehmung einmischt und den äußeren Gegenständen Bestimmungen zukommen lässt, die mangels eines solchen Bezugs auf das Selbst und auf die Sphäre des Eigenen (u. d. h. zugleich auf die Sphäre seiner xpeia im weitesten Sinne) in ihnen überhaupt nicht zu finden wären. M. a. W.: Das Lebewesen beschränkt sich keineswegs darauf, die Außendinge als solche wahrzunehmen. Es setzt sie zum eigenen Wesen in Beziehung und nimmt sie unter ständigem Bezug auf sich selbst wahr. Ja, die äußere Wahrnehmung

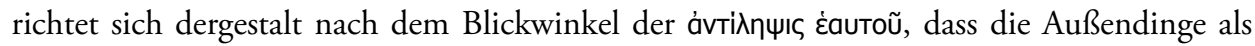
eine Art Umgebung des Selbst wahrgenommen werden ${ }^{27}$. Das ist es, worauf die Tatsache,

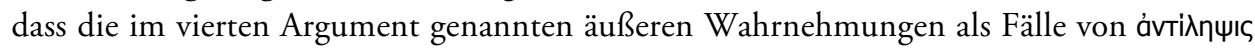
غ̇auтoũ eingestuft werden, letzten Endes hindeutet, nämlich dass die Sphäre des Eigenen gewissermaßen den gesamten Bereich der äußeren Wahrnehmung und somit der Außendinge durchzieht und eine Art Netzwerk von Bezügen des Selbst (von Bezügen zum eigenen Wesen) bildet, das für die Wahrnehmung der Außendinge maßgebend ist ${ }^{28}$. All dies hat zur Folge,

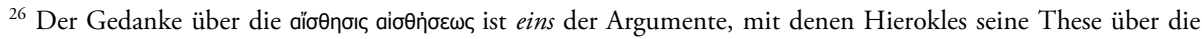

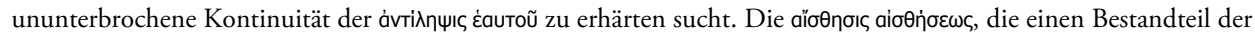

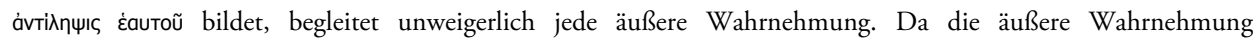

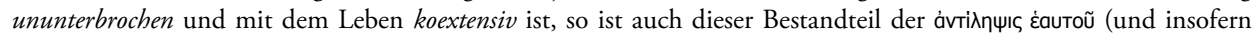
auch die ávтi入пщı દ̇autoũ selbst) ununterbrochen und mit dem Leben koextensiv. Dies bedeutet aber keineswegs,

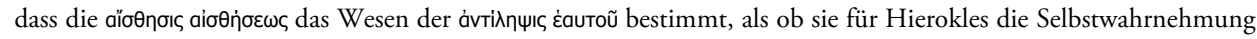
кат' غ̇६охй wäre. Vielmehr bleibt der Leitgedanke nach wie vor derjenige, der oben Anm. 8 dargestellt wurde: Unter

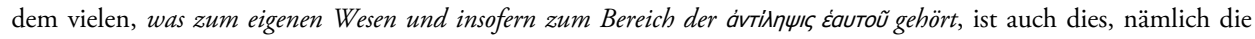

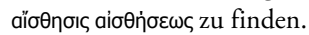

${ }^{27}$ Von "Umgebung" ist in den Fragmenten des Hierokles nicht ausdrücklich die Rede. Seine Erörterungen deuten aber ihrem eigensten Sinne nach auf das fragliche Phänomen.

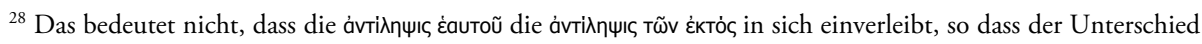

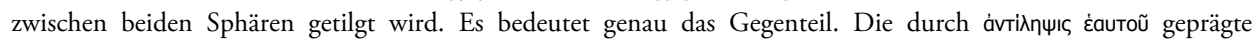
Wahrnehmung zeichnet sich gerade dadurch aus, dass sie das Eigene von dem unterscheidet, was nicht der Sphäre des Eigenen gehört, und dieses als etwas empfindet, was غ̇ктò liegt. Der Unterschied zwischen beiden hier in Frage stehenden Bereichen wird aber nicht von einem freischwebenden, sondern ganz im Gegenteil von einem selbstzentrierten Standpunkt (von dem Standpunkt des Selbst, des Eigenen) aus festgestellt. D. h.: Alles außerhalb der Sphäre des Eigenen Liegende erscheint so, dass es auf den Mittelpunkt, d.h. auf das Selbst bzw. auf das Eigene zurückbezogen wird und sich durch seinen Bezug zum Selbst bzw. zur Sphäre des Eigenen definiert. Die Wahrnehmung des Außen ist zwar nach außen gewandt, erkennt das Äußere als Äußeres und zieht zwischen dem Äußeren und dem Eigenen eine scharfe Trennlinie. Die Wahrnehmung des Äußeren als Äußeren ist aber von Grund aus in dem bezeichneten Sinne selbstzentriert. Und das Äußere als solches ist von Grund auf selbstbezüglich. 
erstens dass alle Außendinge als Peripherie der als Mittelpunkt dienenden Sphäre des Eigenen in Erscheinung treten, und zweitens dass jedes Außending als der Bestandteil dieser Peripherie wahrgenommen wird, welcher sich durch diese und jene konkreten Bezüge zum Selbst bzw. zur besagten Sphäre des Eigenen auszeichnet. In summa: Es gibt keinen Gegenstand der äußeren Wahrnehmung im hierokleischen Sinne, welcher nicht so oder so ja auf vielfältige Weise - im Rückbezug auf den immer mitvernommenen Kern oder Mittelpunkt des Selbst als ein für die Bestimmung der Situation des Selbst irgendwie bedeutender Faktor, d. h. als ein Faktor wahrgenommen wird, dem eine Art „Umgebungskarte“ des Selbst (nämlich die „Umgebungskarte“, deren ein Lebewesen zu seiner Orientierung bedarf) Rechnung tragen muss.

Darin besteht der Kern des hier in Frage stehenden Zentrierungsphänomens, das sowohl den von Hierokles beschriebenen konzentrischen Kreisen des Interesses oder der Anteilnahme als auch den im vierten Argument genannten äußeren Wahrnehmungen innewohnt und die Grundstruktur aller äußeren Wahrnehmung bildet, die es hier herauszuarbeiten galt.

Als Fazit bleibt somit Folgendes festzuhalten. Was oben über die Art und Weise ausgeführt

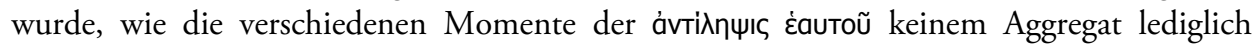
mosaikartig angereihten ávтı $\lambda \dot{ } \dot{\psi \varepsilon ı \varsigma ~ u n d ~ P e r c e p t a ~ e n t s p r e c h e n, ~ s o n d e r n ~ v i e l m e h r ~ d u r c h ~ e i n e n ~}$ sinnvollen Zusammenhang gebunden sind, gilt nicht nur innerhalb der Sphäre des Eigenen

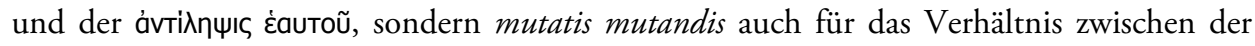

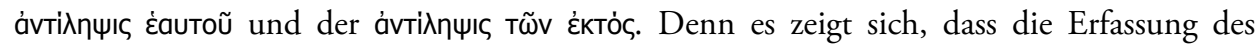
Eigenen und die Erfassung des Äußeren (und die ihnen entsprechenden Bereiche des eigenen Wesens und der äußeren Dinge im hierokleischen Sinne) keine lediglich aneinandergereihten, zusammenhanglosen Sphären darstellen. Das genaue Gegenteil trifft zu. Es hat sich nämlich

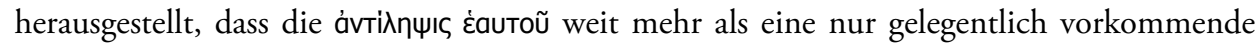
Beilage der äußeren Wahrnehmung oder auch weit mehr als dazugehöriges „Zubehör“ ist, welches zwar jede Wahrnehmung begleitet, aber nur als ganz abgesonderter Bestandteil derselben. Hierokles' Ausführungen in der ウ̇Өıкท่ бтоххішбıৎ deuten vielmehr darauf hin, dass der oben besprochene, der Sphäre des Selbst oder des Eigenen innewohnende und diese Sphäre strukturierende sinnvolle Zusammenhang weit über die Grenzen der besagten Sphäre hinausreicht, ja gewissermaßen den Gesamtbereich der äußeren Wahrnehmung durchzieht. Der fragliche sinnvolle Zusammenhang zwischen den verschiedenen Momenten der Wahrnehmung ist demnach kein regionales, nur einen Teil der Wahrnehmung, sondern vielmehr ein alle Wahrnehmung als solche, ein den Gesamthorizont der Wahrnehmung strukturiendes Phänomen.

Wenn man diese Puzzlestücke, die zwar aus verschiedenen Texten des Hierokles stammen, der Sache nach aber ganz eindeutig zusammengehören, zusammensetzt, so ergibt sich ein

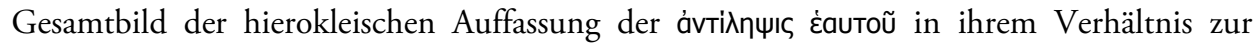

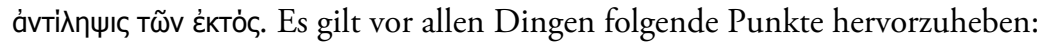

1) Die Komplexität der Sphäre des Eigenen bzw. dessen, was durch Selbstwahrnehmung im hierokleischen Sinne wahrgenommen wird. Die Sphäre des Eigenen umfasst sowohl ä

\footnotetext{
Wenn man hier sagt, dass die Sphäre des Eigenen gewissermaßen den ganzen Bereich der äußeren Wahrnehmung und somit der Außendinge durchzieht, so bedeutet dies, dass der Bezug auf das als Mittelpunkt dienende Selbst bzw. das soeben erwähnte Netzwerk von Bezügen des Selbst den gesamten Bereich der äußeren Wahrnehmung und somit der Außendinge durchzieht und strukturiert.
} 
Ěxદı - all die verschiedenen Elemente, die zum eigenen Wesen gehören oder das eigene

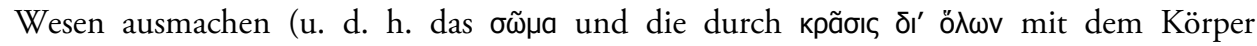
durchgängig und aufs Innigste vereinigte $S e e e^{29}$ ) - als auch die mit all diesen Elementen

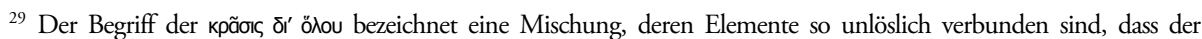

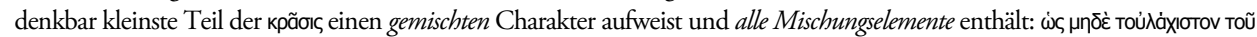

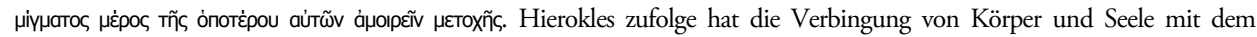
Verhätnis zwischen einem Gefäß und der in ihm eingeschlossenen Flüssigkeit nicht das Geringste zu tun. Die Verbindung von Körper und Seele ist vielmehr mit dem glühenden Eisen zu vergleichen, in welchem es überhaupt keinen, wenn auch

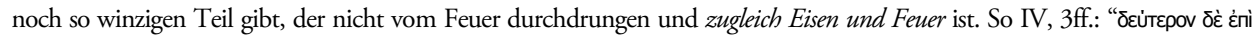

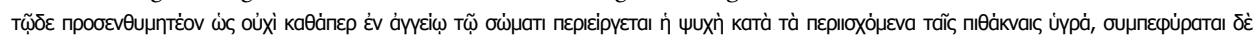

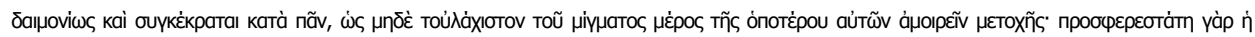

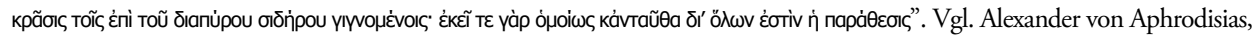
De anima libri mantissa, apud I. Bruns (Hrsg.), Alexandri Aphrodisiensis praeter commentaria scripta minora (Commentaria in Aristotelem Graeca, 2.1), Berlin 1887, S. 115 (=SVF II 797) sowie die zusammenfassende Darstellung der verschiedenen Formen von $\mu \tilde{\xi} \xi$ \, welche in der chrysippschen Mischungslehre unterschieden werden, die bei Alexander von Aphrodisias, $D e$ mixtione, apud I. Bruns (Hrsg.), Alexandri Aphrodisiensis praeter commentaria scripta minora (Commentaria in Aristotelem Graeca, suppl. 2.2). Berlin 1892, S. 213-238, bes. 216-218 (SVF II 473) zu finden ist. Es ist dies nicht der Ort, die kpãøıs ठı' ö\ou zu erörtern, und von der Reihe von Aporien, die sich aus diesem Begriff ergeben, wird hier völlig abgesehen. Vgl. etwa Diogenes Laertius, Vitae philosophorum, hrsg. von M. Marcovich, Stuttgart 1999, VII, 150-151, sowie Alexander von Aphrodisias, De mixtione, a.a.O., S. 221 und zur Diskussion dieses Problemzusammenhangs in der Forschung beispielsweise M. POHLENZ, Die Stoa. Geschichte einer Bewegung, Göttingen 1959, Bd. I, S. 72f., Bd. II, S. 41f., S. Sambursky, Physics of the Stoics, London 1959, S. 15ff., H. Dörrie, Porphyrios' Symmikta Zetemata. Ihre Stellung in System und Geschichte des Neuplatonismus nebst einem Kommentar zu den Fragmenten, München 1959, S. 24ff., R. B. TODD, Alexander of Aphrodisias on Stoic Physics. A Study of De mixtione with Preliminary Essays, Text, Translation and Commentary, Leiden 1976, passim, J. Mansfeld, „Zeno and Aristotle on Mixture“, Mnemosyne 36 (1983), S. 306-310, R. Sharvy, „Aristotle on Mixtures“, Journal of Philosophy 80 (1983), S. 441-448, B. Inwood, „Hierocles: Theory and Argument in the Second Century A. D.“, Oxford Studies in Ancient Philosophy 2 (1984), S. 151-184, bes. 163-164, F. H. Sandbach, Aristotle and the Stoics, Cambridge 1985, S. 33f., M. J. White, „Can Unequal Quantities of Stuffs be Totally Blended?", History of Philosophy Quarterly 3 (1986), S. 379-89, A. A. Long/D. N. Sedley (Hrsg.), The Hellenistic Philosophers, Cambridge 1987, Bd. 1, S. 290ff., Bd. 2, S. 287ff., G. Badalamenti, „Ierocle Stoico e il concetto di ouvaioønoı““, Annali del Dipartamento di filosofia (Università di Firenze) 3 (1987), S. 53-97, bes. 93ff., R. Sorabji, „The Greek Origins of Chemical Combination: Can Two Bodies Be in the Same Place?", Proceedings of the Boston Area Colloquium in Ancient Philosophy 4 (1988), S. 35-63, M. D. Boeri, „El valor de Alejandro de Afrodisia como fuente de la Stoa antigua: (a propósito de pneûma, tónos y krâsis)“, Méthexis 4 (1991), S. 129-136, J. Annas, Hellenistic philosophy of Mind, Berkeley 1992, 47ff., A. A. Long, „Soul and Body in Stoicism“, Phronesis 27 (1982), S. 34-57, bes. 38ff. (=Ders., Stoic Studies, Cambridge 1996, S. 224-249, bes. $230 \mathrm{ff}$.), C.-U. Lee, Oikeiosis. Stoische Ethik in naturphilosophischer Perspektive, Freiburg/München 2002, S. 71ff. In diesem

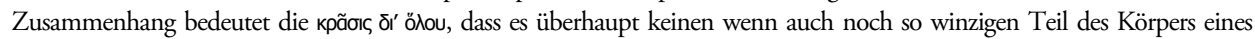
Lebewesens gibt, der nicht mit чuxウ́ verbunden ist - d.h. der nicht wahrgenommen wird, so dass die Wahrnehmung dieses

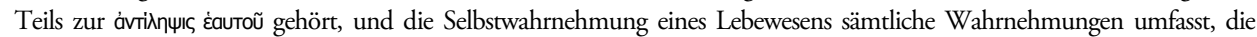

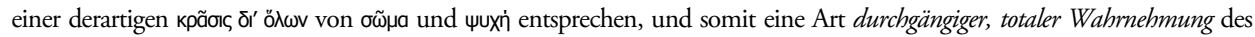

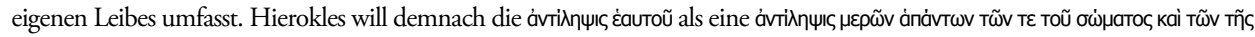
uuxñ (so IV, 51-2) verstanden wissen. Die Forschung hat darauf hingewiesen, dass die von Hierokles dargestellte Lehre wesentliche Züge des von Sherrington geprägten Begriffs von „proprioception“ vorwegnimmt. Vgl. C. Sherrington, The Integrative Action of the Nervous System, London 1908, Ndr.: New Haven 1952, S. 132f., 205f., 335ff., und J. Brunschwig, „The Cradle Argument in Epicureanism and Stoicism“, in: M. Schofield/G. Stricker (Hrsg.), The Norms of Nature. Studies in Hellenistic Ethics, Cambridge/Paris 1986, S. 113-143, bes. 137, G. Bastianini/A. A. Long, op. laud., S. 387ff., 416f., bes. 421, A. A. Long, „Hierocles on Oikeiôsis and Self-Perception“, in: K. J. Boudouris (Hrsg.), Hellenistic Philosophy, Bd. I, Athens 1993, S. 93-104, hier 97ff. (=A. A. Long, Stoic Studies, Berkley/Los Angeles/London 1996, S. 258ff.), R. Radice, “Oikeiosis”. Ricerche sul fondamento del pensiero stoico e sulla sua genesi, Milano 2000, S. 191f., C. Gill, „Psychophysical Holism in Stoicism and Epicureanism“, in: R. A. H. King (Hrsg.), Common to Body and Soul. Philosophical Approaches to Explaining Living Behaviour in Greco-Roman Antiquity, Berlin 2006, S. 200-231, bes. 216, C. Gill, The Structured Self in Hellenistic and Roman Thought, Oxford 2006, S. 40ff. , B. Collette-Ducic/S. Delcomminette, "La théorie stoïcienne du

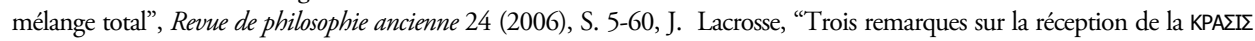


aufs engste zusammenhängenden xpвia-Möglichkeiten (d. h. nicht zuletzt auch das sehr komplexe Geflecht der Zusammenhänge zwischen ă ह̌xદı und den xрعĩa).

2) Diese Sphäre ist aber keineswegs abgekapselt. Wie Hierokles betont, bildet sie den Mittelpunkt des gesamten Wahrnehmungshorizontes, und zwar dergestalt, dass sie sowohl den terminus ad quem allerhand von der Peripherie her auf sie zu kommender, die xpeia des Selbst im weitesten Sinne affizierender Wirkungen der Außenwelt auf das eigene Wesen als auch den terminus a quo verschiedener Wirkungen des eigenen Wesens auf die Außenwelt darstellt. Dabei verhält es sich so, dass die verschiedenen Momente des eigenen Wesens (ä Ěxદı) und die ihnen entsprechenden verschiedenen möglichen xpria-Richtungen durch ihren Zusammenhang mit den Außendingen die Basis für ein breites Spektrum verschiedener auf das Selbst bzw. auf die Sphäre des Eigenen bezogener Beschaffenheiten äußerer Dinge bieten $^{30}$. Hierokles' Beschreibung der Wahrnehmung und ihrer Struktur deutet also auf ein

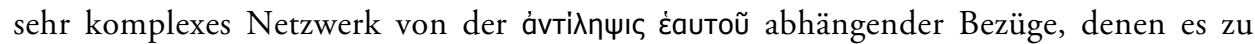

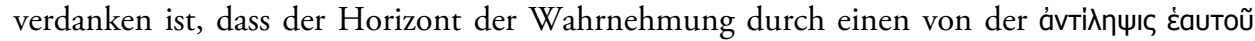
getragenen Gesamtzusammenhang strukturiert ist und ein immer um den Mittelpunkt des Selbst und seiner Sphäre kreisendes Ganzes bildet.

3) Hierbei verhält es sich so, dass das fragliche Netzwerk von auf das Selbst und die Sphäre des Eigenen zentrierten Rückverweisen und in diesen Rückverweisen wurzelnden Beschaffenheiten der Außendinge sehr umfangreich sein kann. Diesbezüglich gilt es vor allen Dingen zweierlei zu betonen. Die Rede von Umgebung soll nicht dazu verleiten zu meinen, dass die von Hierokles beschriebenen Sachverhalte nur für die Sphäre der das eigene Wesen unmittelbar umgebenden Außendinge gilt. Das Netzwerk der sich ringsum verbreitenden, alles als Umgebung um den gemeinsamen Zentralpunkt des eigenen Wesens vereinigenden Bezüge des Selbst kann vielmehr die außerordentliche Spannweite aufweisen, auf die das Gleichnis der immer ausgreifenden konzentrischen Kreise hindeutet (wobei nicht zu vergessen ist, dass die von Hierokles genannten Kreise des Interesses oder der Anteilnahme im Grunde nur einen Teil eines noch viel komplexeren Zusammenhangs darstellen). Hinzu kommt aber noch ein anderer Aspekt. Dieses Netzwerk sich ringsum verbreitender, alles als Umgebung um den gemeinsamen Zentralpunkt des eigenen Wesens vereinigender Bezüge des Selbst ist andererseits auch dadurch gekennzeichnet, dass es durch die von Hierokles geschilderten Kontraste zwischen Nähe und Ferne (wohlgemerkt zwischen einer funk-

stö̈cienne chez Plotin”, Revue de philosophie ancienne 25 (2007), S. 53-66, sowie D. COHEN, "Aperçu de la réception de la doctrine stoïcienne du mélange total dans le néoplatonisme après Plotin", ebd., S. 67-100.

${ }^{30}$ Hierokles' Ausführungen lenken die Aufmerksamkeit auf den phänomenalen Befund, der darauf hinweist, dass die

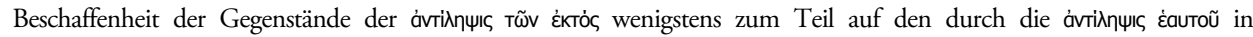
Erscheinung tretenden Mittelpunkt des gesamten Wahrnehmungshorizontes, nämlich das Selbst und die Sphäre des Eigenen zurückverweist und in diesem Sinne selbstbezüglich ist. Es fragt sich aber, a) wie das Wesen und die Struktur derartiger auf die Selbstwahrnehmung bzw. auf die Sphäre des Eigenen zurückverweisender und in diesem Sinne selbstbezüglicher Beschaffenheiten äußerer Gegenstände eigentlich zu verstehen sind, und b) ob das hier in Frage Stehende

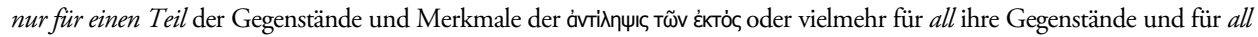

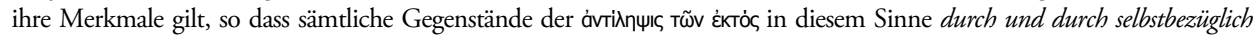
sind. Diese Fragen werden von Hierokles nicht gestellt. Und es muss hier dahingestellt bleiben, wie sie zu beantworten

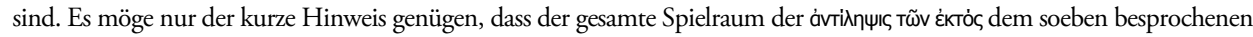

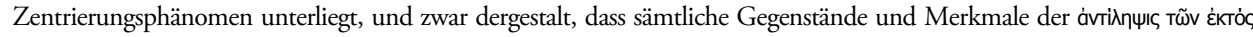
grundsätzlich als Umgebungsgegenstände und -merkmale wahrgenommen werden. 
tionsbezogenen, nicht nur einer räumlichen oder zeitlichen Nähe und Ferne) bzw. zwischen selbstbezogenem Vordergrund und Hintergrund - oder vielmehr durch die abgestufte, vielschichtige Reihe von Kontrasten und Kreisen strukturiert ist, auf die das besagte Gleichnis des Hierokles hindeutet, so dass es sich nicht nur durch seine Weite, sondern sozusagen auch durch seine Tiefe auszeichnet ${ }^{31}$.

Hierbei ist allerdings anzumerken, dass der Horizont der Wahrnehmung nicht unbedingt in jedem Fall diese Spannweite bzw. diese abgestufte und vielschichtige Struktur aufweisen muss. Aber, wie dem auch sei, soviel bleibt festzuhalten: Das Grundphänomen der Selbstwahrnehmung im hierokleischen Sinne ist seinem Wesen nach imstande, einen so umfangreichen, vielschichtigen und „tiefen“ Horizont der äußeren Wahrnehmung oder der Außendinge um die Sphäre des Selbst zu vereinigen und dieser Sphäre als ihre Umgebung oder Peripherie anzugliedern. Dies bedeutet wiederum Folgendes: Davon abgesehen, ob die Umgebung des Selbst eine derartige Weite und Tiefe aufweist oder nicht, der gesamte Horizont der äußeren Wahrnehmung stellt unabdingbar eine solche, von dem Bezug zum gemeinsamen Zentralpunkt des Selbst zusammengehaltene, das Selbst und seine Umgebung umfassende Alleinheit dar.

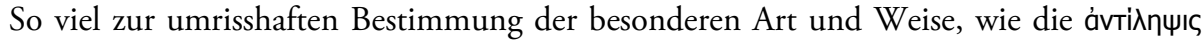

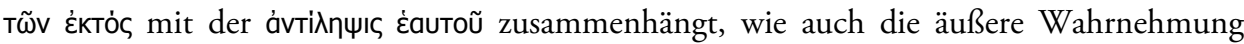
durch ihren selbstreferentiellen, auf die Sphäre des Eigenen zentrierten Charakter durch und durch geprägt ist, und wie der Horizont der Wahrnehmung ein durch seine Erweiterbarkeit zwar offen bleibendes, durch seinen an die Sphäre des Selbst gebundenen, auf diese Sphäre zentrierten „Blickwinkel“ jedoch geschlossenes Ganzes bildet.

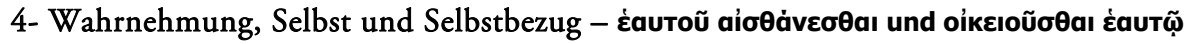

Das Wichtigste bleibt aber gewissermaßen noch zu betrachten. Denn es fragt sich, was die Sphäre des Eigenen zu einer solchen macht. Worin besteht eigentlich das Selbst, welches demnach sozusagen das A und das O der Selbstwahrnehmung und den Mittel- und Quellpunkt dieses ganzen Netzwerkes von Bezügen bildet, den Mittel- und Quellpunkt, um welchen die

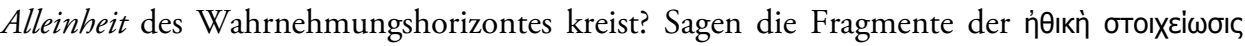
auch etwas dazu, oder wird diese Frage einfach mit Stillschweigen übergangen?

Ehe man diese Frage zu beantworten versucht, muss man aber noch einen Punkt ins Auge fassen, welcher für ihre Beantwortung unerlässlich ist, ja ohne dessen Mitberücksichtigung das Ausgeführte am Entscheidendsten geradewegs vorbeizielt und das Spezifikum der

\footnotetext{
${ }^{31}$ Zwar verhält es sich so, dass die äußersten Kreise so entfernt sind, dass sie beinahe keine Rolle mehr spielen, und ihr Zusammenhang mit dem Zentralpunkt allem Anschein nach nur sehr lose ist. Dies bedeutet aber nicht, dass sie in keinem Zusammenhang mit dem Mittelpunkt stehen oder nicht mehr auf den Mittelpunkt relativ sind. Der Bezug wird in der Tat nicht unterbrochen: Zum Beispiel in dem hierokleischen Gleichnis der konzentrischen Kreise zeichnen sich die äußersten Kreise eben deswegen durch die verschwindend geringe Intensität des ihnen entsprechenden Interesses aus, weil sie vom Zentralpunkt des Selbst entfernt sind. D. h.: Das fragliche Entferntsein und die mit dem Entferntsein korrelierende geringe Intensität des Interesses sind und bleiben eine Art von selbstbezüglicher, auf den Mittelpunkt des eigenen Wesens relativer Beschaffenheit, so dass dem Entferntesten eben nur im Bezug auf den Mittelpunkt des Selbst dieses Prädikat und die ihm entsprechende geringe Intensität des Interesses zukommt.
} 
hierokleischen Auffassung der Wahrnehmung verfehlt. Es geht nämlich um die sog.

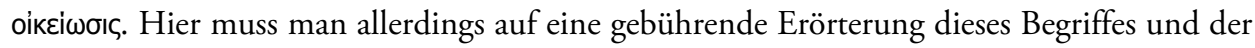
ihm entsprechenden Konstellation von Phänomenen verzichten und sich mit einem groben Umriss des Allerwesentlichsten begnügen.

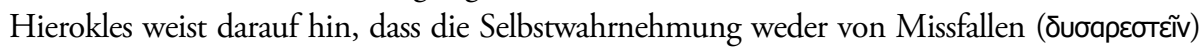
noch von Gleichgültigkeit (à $\rho \varepsilon n \tilde{\omega} \varsigma$ I̋

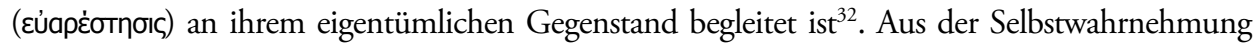
fließt natürlich das, was er mit Hilfe einer klassischen stoischen terminologischen Wendung

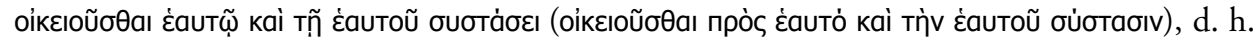
ein Zu-sich-selbst-geneigt-werden, Sich-selbst-zugetan- oder -zugewandt-werden nennt (die lateinische Übersetzung dieser Wendung, conciliari oder commendari, d. h. also eine Art Sich-selbst-empfohlen-werdens kann auch dazu verhelfen, den Sinn der stoischen Formel besser zu verstehen $)^{33}$. Die Selbstwahrnehmung ist also mit Neigung oder Zuneigung zum eigenen

32 VI, 27-30, 40-49, VII, 16, 49. Vgl. Diogenes Laertius, Vitae philosophorum, hrsg. von M. Marcovich, Stuttgart 1999, VII, 85.

${ }^{33}$ VI, 51-53, VII, 16, 20, 49-50, IX, 8-9. Vgl. etwa Diogenes Laertius, op. Laud., VII, 85, Alexander von Aphrodisias, De anima libri mantissa, op. laud., S. 150, 162, Plutarch, De Stoicorum repugnantiis, R. Westman (Hrsg.), Plutarchi moralia, Bd. 6.2, Leipzig 1959, 1038b, Cicero, De Finibus bonorum et malorum, hrsg. von T. Schiche, Leipzig 1915, Ndr. Stuttgart 1961, III, 16, II, 33, IV, 34, Seneca, Philosophische Schriften, Darmstadt 1995, Bd. 4, Ad Lucilium epistulae morales, CXXI, 5, 10, 11, 14, 17, 21, C. Wachsmuth/O. Hense (Hrsg.), Ioannis Stobaei anthologium, Berlin 1884-1921, Ndr. 1958, II, 7 (II, 118). Zur weiteren Diskussion der fraglichen stoischen Formel und ihrer Bedeutung, s. etwa R. Philippson, „Das erste Naturgemässe“, Philologus 87 (1932), S. 445-466, M. Pohlenz, Grundfragen der stoischen Philosophie, Göttingen 1940, S. 12, S. G. Pembroke, „Oikeiosis“, in: A. A. Long (Hrsg.), Problems in Stoicism, London/Atlantic Highlands 1971, S. 114-149, bes. 115f., G. B. Kerferd, „The Search for Personal Identity in Stoic Thought“, Bulletin of the John Rylands University Library of Manchester 55 (1972), S. 177-196, bes. 179ff., H. Görgemanns, „Oikeiosis in Arius Didymus“, in: W. W. Fortenbaugh (Hrsg.), On Stoic and Peripatetic Ethics. The Work of Arius Didymus, New Brunswick (N.J.)/London 1983, S. 165-189, bes. 183ff., J. Brunschwig, „The Cradle Argument in Epicureanism and Stoicism“, in: M. Schofield/G. Stricker (Hrsg.), The Norms of Nature, op. laud., S. 136ff., B. Inwood, „The Two Forms of oikeiôsis in Arius and the Stoa. Comments on Professor Görgemanns' Paper“, ebd., S. 190-201, J. Brunschwig, „The Cradle Argument in Epicureanism and Stoicism“, op. laud., bes. S. 136ff., G. Badalamenti, „Ierocle Stoico e il concetto di ouvaiOnбıc“, op. laud., S. 78f., G. Schönrich, „Oikeiosis - Zur Aktualität eines stoischen Grundbegriffs“, Philosophisches Jahrbuch 96 (1989), S. 34-51, T. Engberg-Pedersen, The Stoic Theory of Oikeiosis. Moral Development and Social Interaction in Early Stoic Philosophy, Aarhus 1990, S. 240, R. Sorabji, Animal Minds and Human Morals. The Origins of the Western Debate, Ithaca (N.Y.) 1993, S. 122f., J. Annas, The Morality of Happiness, Oxford/N.Y. 1993, S. 262f., A. A. Long, „Hierocles on Oikeiôsis and Self-Perception“, in: K. J. Boudouris (Hrsg.), Hellenistic Philosophy, Bd. I, Athens 1993, S. 93-104, bes. 966 (=A. A. Long, Stoic Studies, op. Laud., S. 256f.), B. Inwood/P. Donini, „Stoic Ethics“, in: K. Algra/J. Barnes et al. (Hrsg.), The Cambridge History of Hellenistic Philosophy, Cambridge 1999, S. 675-738, bes. 677f., R. Bees, Die Oikeiosislehre der Stoa. I Rekonstruktion ihres Inhalts, Würzburg 2004, S. 23, Anm. 17, 202ff. Zur lateinischen Übersetzung der stoischen Formel vgl. Robert Fischer, De usu vocabulorum apud Ciceronem et Senecam Graecae philosophiae interpretes, Freiburg i. Br. 1914, S. 62-71. Schließlich bleibt in diesem Zusammenhang noch Folgendes anzumerken: Die von Hierokles verwendete

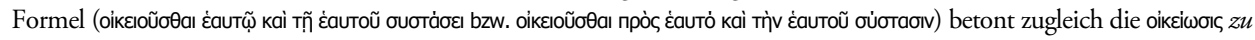

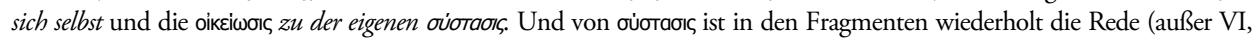
52 und VII, 50, vgl. auch IX, 1). ¿úoraøı (status, constitutio, vgl. Robert Fischer, a.a.O., S. 72f.) bezeichnet allem Anschein nach die Konstitution bzw. die naturgegebene, ,angemessene“ Verfassung eines Lebewesens. Ob die stoische Formel einen

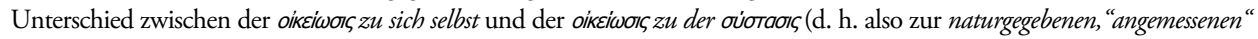
Verfassung) voraussetzt, und worin dieser Unterschied genau besteht, ist eine in der Forschung umstrittene, noch nicht ausreichend geklärte Frage. Vgl. z. B. J. Brunschwig, "The Cradle Argument in Epicureanism and Stoicism“, in: M. Schofield/G. Stricker (Hrsg.), The Norms of Nature. Studies in Hellenistic Ethics, Cambridge/Paris, 1986, S. 113-143, bes. 139, G. Bastianini/A. A. Long, op. laud., S. 436ff., bes. 439, A. A. LONG, „Hierocles on Oikeiôsis and Self-Perception“, op. laud., hier 98, Anm 14 (=A. A. Long, Stoic Studies, Berkeley/L.A./London 1996, S. 257), R. Radice, "Oikeiosis". 
Wesen, mit Anhänglichkeit an das eigene Wesen unlöslich verbunden. Es handelt sich aber nicht nur um eine vage oder laue Zuneigung, sondern vielmehr um etwas Tiefverwurzeltes und Gewaltiges, um eine ganz entschiedene und radikale Parteinahme für sich selbst, die den Betroffenen in diese Parteinahme mitreißt und an sie unausweichlich bindet. Ja, die Selbstwahrnehmung ist mit einer Art Selbstliebe unzertrennlich verbunden - Hierokles spricht

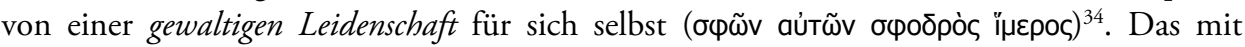

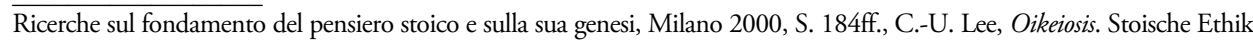
in naturphilosophischer Perspektive, Freiburg/München 2002, S. 68ff.. Es ist dies nicht der Ort, auf diese Frage ausführlich einzugehen. So viel sei jedoch in aller Kürze bemerkt: 1) Es ist nicht auszuschließen, dass in der fraglichen

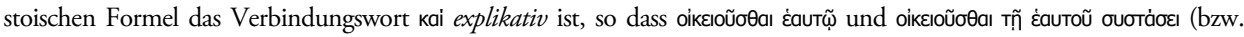

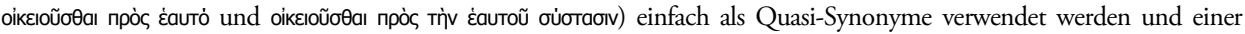
Begriffsdoppelung entsprechen. An und für sich kann die stoische Formel also dahingehend interpretiert werden, dass es

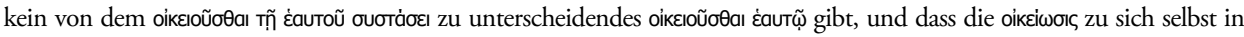

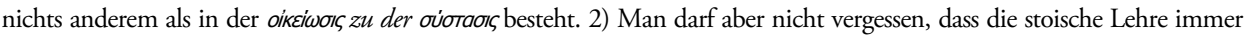
wieder den Unterschied zwischen der Sphäre des Eigenen und all dem aufs Schärfste betont, was außerhalb dieser Sphäre liegt. Dies scheint aber zu bedeuten, a) dass ein Unterscheidungsprinzip zwischen den fraglichen zwei Bereichen eine ausschlaggebende Rolle spielt, und b) dass dieses Unterscheidungsprinzip kein anderes ist als das, was dem Grundcharakter der Sphäre des Eigenen als solchen zugrundeliegt, nämlich die Grundbestimmung „Selbst“. Diese Grundbestimmung ist es, die den gemeinsamen Nenner aller verschiedenen Momente der oúoraøı bildet, diese verschiedenen Elemente verbindet und ihnen ihr eigentümliches Gepräge und ihre hervorragende, einzigartige Bedeutung verleiht. Dies legt wiederum nahe,

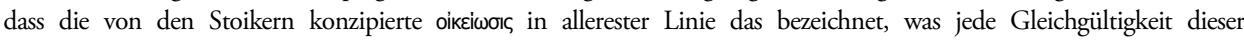
Grundbestimmung des Selbst und all dem gegenüber unterbindet, was sich durch die fragliche Grundbestimmung

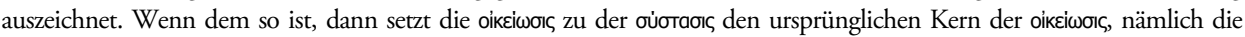

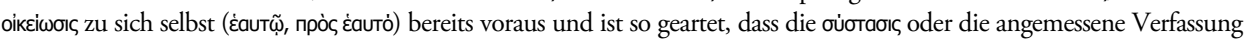
nur insofern zu etwas Nichtgleichgültigem wird, als es sich eben um die eigene Verfassung (d. h. also um die angemessene Verfassung des Selbst) handelt. Und dieser Zusammenhang ist es dann, der sich in der hier in Frage stehenden stoischen

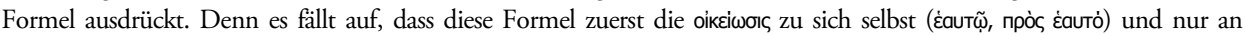

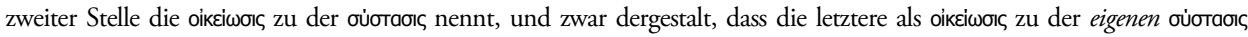

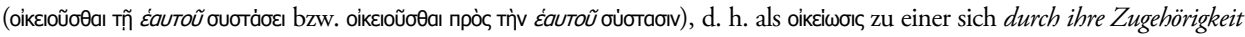
zum Selbst auszeichnenden oúoraoı ganz eindeutig charakterisiert wird. 3) Der Sache nach scheint ein Unterschied

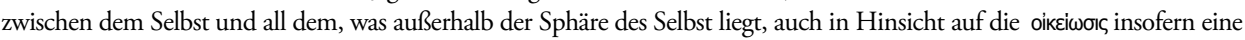
Rolle zu spielen, als es nicht ohne weiteres direkt eine gewisse Verfassung als solche, $\mathrm{d}$. h. eine niemandem gehörende Verfassung, auch nicht eine einem anderen gehörende Verfassung, sondern vielmehr eine als Selbst empfundene bzw. durch Zugehörigkeit zum Selbst geprägte Verfassung ist, die zum Gegenstand eines nichtgleichgültigen, an diese Verfassung bindenden, sie beschützenden, für sie Sorge tragenden Verhaltens wird. Also das, dem es zu verdanken ist, dass das Selbst sich selbst empfohlen wird, fuir sich selbst Partei nimmt und in diesem Sinne um sich selbst bemüht ist, stellt gleichsam die

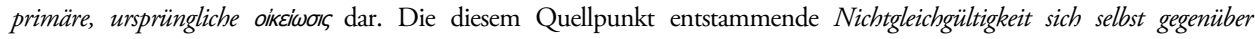
überträgt sich gleichsam auf die oúođaøı, indem eine gewisse Verfassung als angemessen festgesetzt und sozusagen zum Maßstab des Selbst wird, und das Selbst an den fraglichen Maßstab so gebunden ist, dass sein Für-sich-selbst-ein-Anliegensein und Um-sich-selbst-bemüht-sein auch dieser Verfassung (diesem Muster oder Maßstab seines Wesens) gilt und das fragliche Wesen an diesem Muster oder Maßstab seines Wesens hängen lässt. M. a. W.: Das Sich-selbst-gegenüber-nichtgleichgültig-sein (die oikeiwois zu sich selbst) nimmt die Gestalt eines Seiner-angemessenen-Verfassung-gegenüber-nicht-

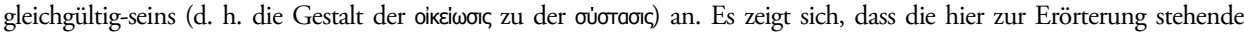

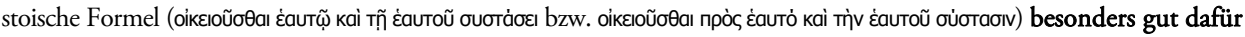
geeignet ist, diesen wesentlichen Zusammenhang genau auszudrücken. Denn die stoische Formel spricht von einer

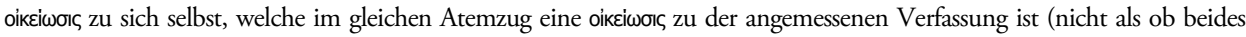

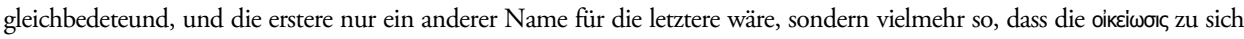

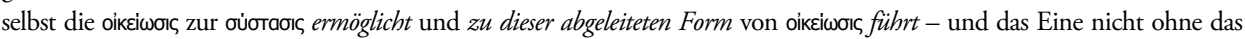
Andere stattfindet). Zusammenfassend bleibt demnach festzuhalten, dass die zwei in der stoischen Formel genannten

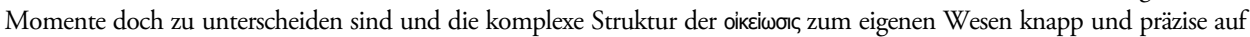
den Punkt bringen.

${ }^{34}$ VII, 3-4. Auch von pi৯autia ist VII, 24 die Rede. 
Selbstwahrnehmung begabte Lebewesen ist daher von einem Streben, das eigene Wesen zu erhalten (unversehrt zu erhalten) und zu entfalten bzw. alles, was dieses Wesen fördert, zu suchen und zu pflegen, durchdrungen. Kurz: In dem mit Selbstwahrnehmung begabten Lebewesen regt sich ein ununterdrückbarer, unwiderstehlicher Trieb oder Drang nach Selbsterhaltung und Selbstförderung ${ }^{35}$. Dieses Wesen lässt sich sozusagen von sich selbst berühren und ist für sich selbst ein Anliegen. Es kann nicht umhin, für sich selbst Sorge zu tragen, um sich selbst bemüht zu sein und sich für sich selbst einzusetzen. Das Sein des sich selbst wahrnehmenden Lebewesens ist demnach kein bloßes Sein und seine Selbstwahrnehmung ist auch keine bloße Selbstwahrnehmung. Sein Sein und seine Selbstwahrnehmung entsprechen

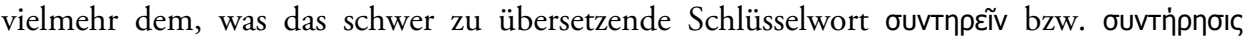
غ̇autoũ auf den Punkt bringt, nämlich „Erhaltung“ und „Bewahrung“. D. h: Das Sein des sich selbst wahrnehmenden Lebewesens zeichnet sich dadurch aus, dass es stets über sein jeweiliges Gegebensein hinausgeht, seiner Erhaltung zustrebt und mit einem auf das eigene Wesen aufpassenden, das eigene Wesen behütenden und beschützenden, um seine Erhaltung und Förderung bemühten, sich für sein Wesen verwendenden Bewachen, Sorgen, Sich-in-achtnehmen unzertrennlich verbunden ist ${ }^{36}$.

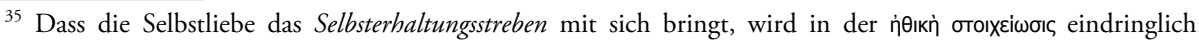
betont, und zwar dergestalt, dass Hierokles verschiedene Aspekte des davon herrührenden, auf Selbsterhaltung

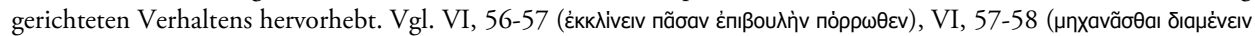

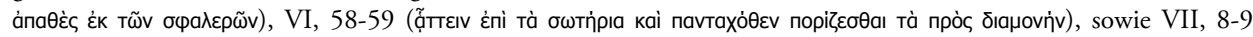

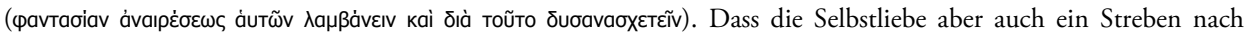
Selbstförderung, d. h. ein Streben, das eigene Wesen zu entfalten (bzw. alles, was dieses Wesen fördert, zu suchen und zu pflegen) nach sich zieht, wird in den Fragmenten des Hierokles nicht eigens betont. Es ist die Frage, ob das Streben nach Serlbsterhaltung von dem Streben nach Selbstförderung völlig unabhängig und getrennt sein kann -

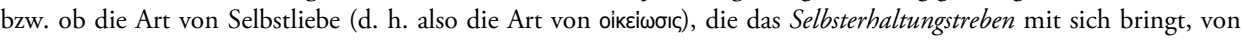
derjenigen zu unterscheiden ist, welche das Streben nach Selbstförderung hervorruft - oder ob es sich nicht vielmehr so verhält, dass beide unauflöslich aneinander gebunden sind.

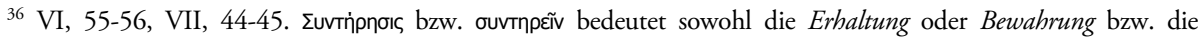

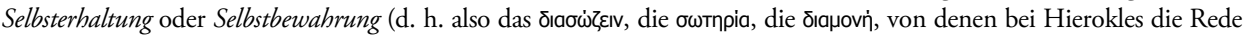
ist) als auch die Bewachung oder Beobachtung (nicht zuletzt auch die auf Selbsterhaltung gerichtete, nach

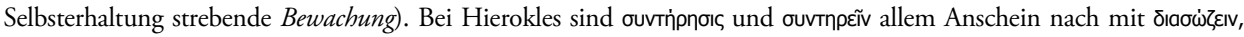

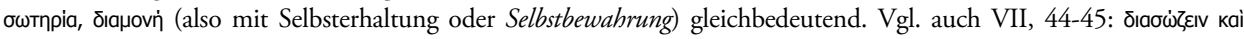

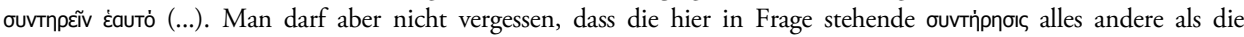
tatsächlich erfolgende Fortsetzung oder Erhaltung eines Wesens bedeutet, welches sich seiner Erhaltung oder Nichterhaltung gegenüber völlig gleichgültig verhält (so dass die tatsächlich erfolgende Erhaltung einfach geschieht, ohne dass das fragliche Wesen sich im Voraus zu ihr verhält, ihr zustrebt, etc.). Das genaue Gegenteil trifft hier zu. Denn es handelt sich in diesem Zusammenhang vielmehr um eine irgendwie entworfene, vorweggenommene, bereits vor ihrem tatsächlichen Eintreten eine ausschlaggebende Rolle spielende ouvrípnoıs oder Selbsterhaltung, welche so beschaffen ist, dass sie von einem das eigene Wesen behütenden und beschützenden, um seine Erhaltung bemühten, sich für sein Wesen verwendenden Bewachen oder Sorgen insofern nicht zu trennen ist, als sie nur als Korrelat eines solchen bewachenden oder sorgenden Verhaltens stattfinden und ihre ausschlaggebende Rolle spielen kann. Die hier in Frage

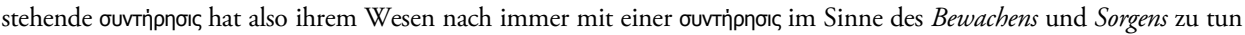
und entspricht durchaus dem, was auch in den lateinischen Darstellungen stoischen Gedankengutes zu finden ist, beispielsweise bei Cicero, de natura deorum II, 124 ("conservandi sui custodia"), de officiis I, 11 ("se, vitam corpusque tueri", vgl. auch de finibus, V, 24, 40), oder de finibus, IV, 34 ("in se conservando occupatum esse"). Zur weiteren

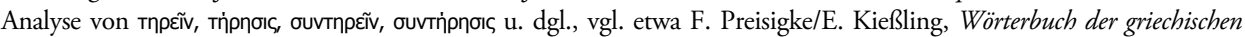
Papyrusurkunden, Bd. II, Berlin 1927, Sp. 552, 597f., Suppl. 1 (1940-1966), Amsterdam 1969, S. 261, 268, Supl. 2 (1967-1976), Wiesbaden 1991, S. 188, 194, Suppl. 3 (1977-1988), Wiesbaden 2000, S. 314, 323, J.H. Moulton/G. Milligan, The Vocabulary of the Greek Testament, London 1949, S. 614, 633f., H. Riesenfeld, in: G. Kittel/G. Friedrich (Hrsg.), Theologisches Wörterbuch zum Neuen Testament, Bd. 8, Stuttgart/Berlin 1969, S. 139-151. 
Dies bedeutet aber, wie leicht zu sehen ist, dass die ai̋ø indifferente, teilnahmslose, lediglich registrierende Kenntnisnahme vollkommen gleichgültiger Fakta oder Begebenheiten ist, die im Grunde das wahrnehmende Wesen nichts angehen. Das wahrnehmende Wesen ist kein „reiner Zuschauer“ und die Wahrnehmung ist kein gleichgültiges Verhalten, in dem es um gar nichts geht. Hierokles zufolge verhält es sich

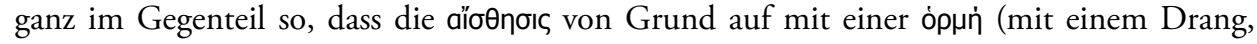

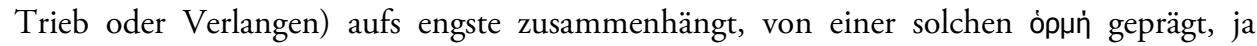

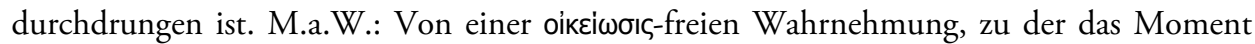

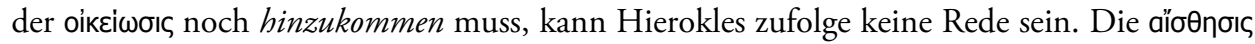
ist wesensmäßig spannungsgeladen, sie gehört immer zu einem nichtgleichgültigen Verhalten und findet nur im Rahmen eines solchen nichtgleichgültigen Verhaltens statt. Alles Wahrnehmen ist an und für sich schon ein Sich-von-dem-Wahrgenommenen-so-oder-so-betreffenoder angehen-lassen. Und jedes Wahrgenommene wird eben als das wahrgenommen, was das wahrnehmende (u. d. h. zugleich: strebende) Wesen so oder so, auf diese oder jene konkrete

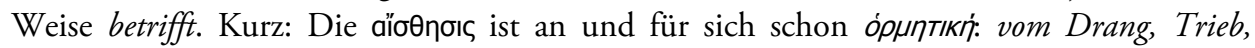
Neigung durchpulst - und zwar so, dass die fragliche ò $\mu \eta \dot{~ d i e ~ o ̀ \rho \mu n ~ d e r ~ о і к \varepsilon i \omega \sigma ı, ~ d . h . ~ e i n e ~ a u f ~}$ das Selbst gerichtete, sich um das Selbst bekümmernde, für Selbsterhaltung und Selbstförderung

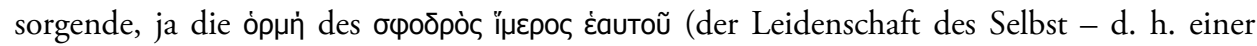
unbedingten Ergebenheit gegenüber seinem eigenen Wesen) ist.

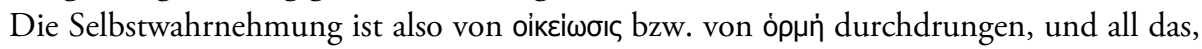
was weiter oben über die Sphäre des Eigenen, ihre verschiedenen Bestandteile (ă ع̌xદı, die verschiedenen $x p \varepsilon i a-R i c h t u n g e n)$ und ihren Zusammenhang ausgeführt wurde, ist entsprechend zu ergänzen. Es ist vor allen Dingen hervorzuheben, dass der sinnvolle Zusammenhang, der

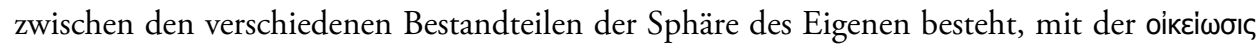
so zusammenhängt, dass es diese ist, die die Basis für den hier in Frage stehenden Sinn schafft bzw. die Maßstäbe für den fraglichen sinnvollen Zusammenhang setzt. Entsprechendes

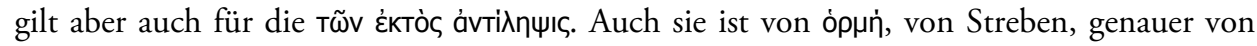

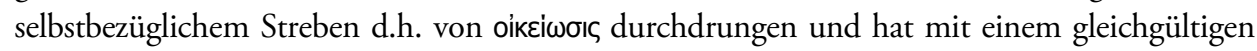
Verhalten nicht das Geringste zu tun. Und all das, was oben über den sinnvollen

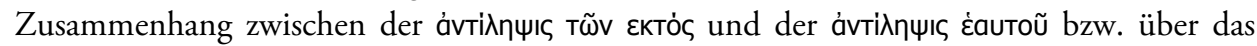
Netzwerk von Bezügen des Selbst ausgeführt wurde, welche den Gesamtbereich der äußeren Wahrnehmung durchziehen und strukturieren, ist entsprechend zu ergänzen. Selbstbezüge das bedeutet in diesem Zusammenhang immer: Bezüge des sich um sich selbst kümmernden Selbst. Kurz: Alle äußere Wahrnehmung ist im Grunde genommen nichts anderes als бuvтn்рпбוৎ in dem oben besprochenen Sinne. Eben deswegen ist sie durchgängig selbstbezüglich

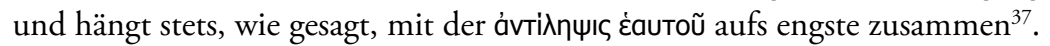

\footnotetext{
${ }^{37}$ Selbst wenn die Selbstwahrnehmung, wie Hierokles geltend zu machen versucht, eine Grundvoraussetzung der

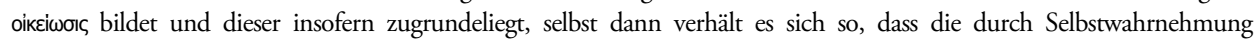
ermöglichte und hervorgerufene oikeiwors die Selbstwahrnehmung gleichsam in Mitleidenschaft zieht, so dass diese nichts

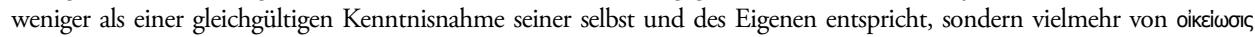

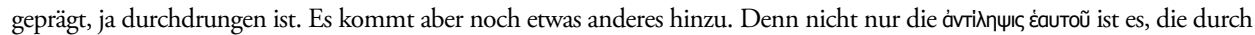

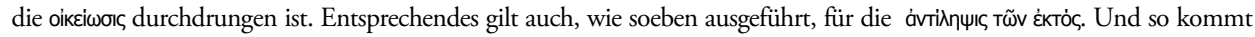

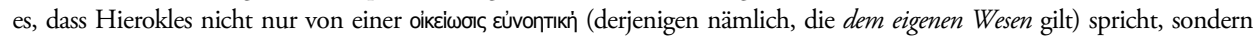

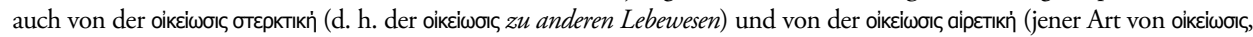




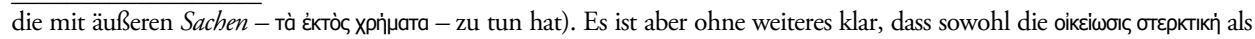

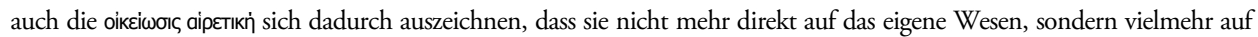
Gegenstände der äußeren Wahrnehmung (in dem hier in Frage stehenden Sinne) bezogen sind. Vgl. IX, 3-10: (...) ウ่ $\mu \varepsilon \dot{\varepsilon}$

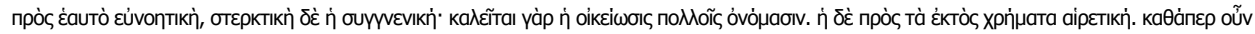

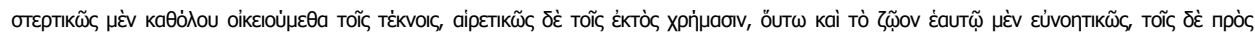

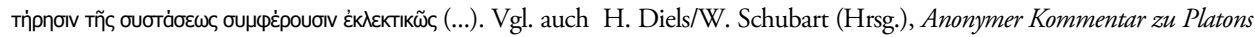
Theaetet (Papyrus 9782) nebst drei Bruchstücken philosophischen Inhalts (Pap. N.8;Pap. 9766.9659), Berlin 1905, G. Bastianini/D. N. Sedley (Hrsg.) Commentarium in Platonis „Theaetetum“, PBerol. Inv 9782, in: Corpus dei Papiri Filosofici Greci e Latini. Testi e lessico nei papiri di cultura greca e latina. Parte III: Commentari, Firenze 1995, S. 227-562, VII, 26-VIII, 6, sowie Alexander von Aphrodisias, De anima libri mantissa, in: I. Bruns (Hrsg.), Alexandri Aphrodisiensis praeter commentaria scripta minora, Berlin 1887, S. 101-186, bes. 162. Es ist dies nicht der Ort, diese verschiedenen Begriffe und die ihnen entsprechenden Verzweigungen des oikeiwors-Phänomens sowie ihren Zusammenhang (geschweige denn das Verhältnis zwischen den genannten verschiedenen Darstellungen der hier in Frage stehenden stoischen Lehre) zu

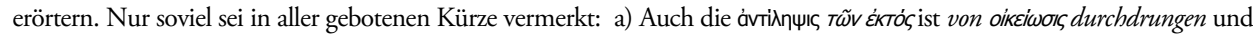
besitzt ihrem Wesen nach den Charakter eines nichtgleichgültigen Verhaltens, mit der Folge, dass die entsprechenden

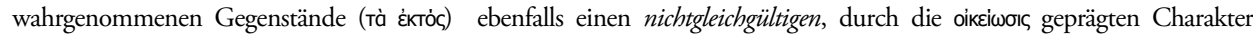

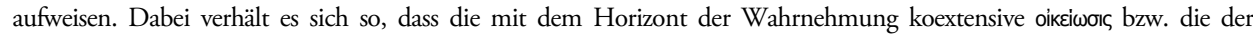

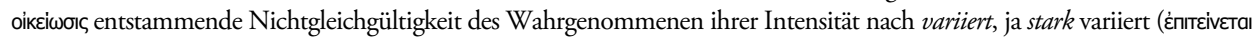

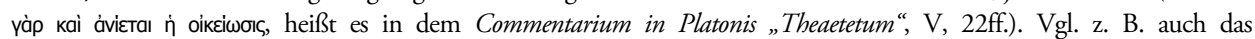
Commentarium in Platonis "Theaetetum“, V, 14ff., VI, 3ff., Stobaios, Anthologium, II, 7 (II, 120f.), Cicero, De officiis, I, xvii, 53ff., Laelius, V, 19, Alexander von Aphrodisias, De anima libri mantissa, 162. Der Gesamtbereich des nichtgleichgültigen Verhaltens eines Lebewesens und der ihm entsprechenden, jedem Wahrgenommenen innewohnenden

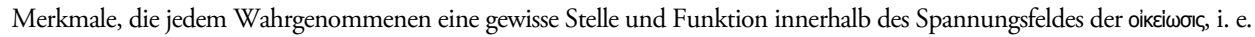
des Nichtgleichgültigen zuweisen, bildet einen sehr komplexen Stufenbau. Die konzentrischen Kreise des Fragments aus dem Anthologium des Stobaios versinnbildlichen, wie ausgeführt, die eigentümliche Struktur dieser Variation, welche somit

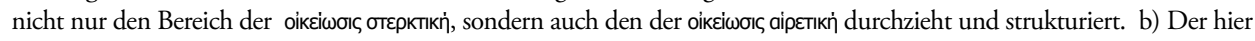
in Frage stehende Stufenbau hängt, wie aus dem Stobaiosfragment ebenfalls hervorgeht, mit dem Hauptgegensatz zwischen

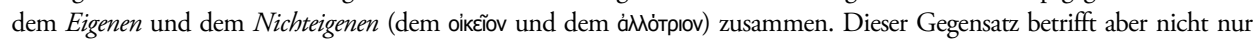

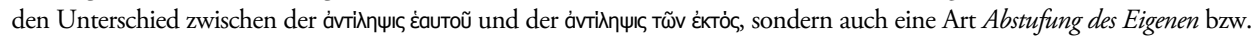
dessen, was mit dem Eigenen im Zusammenhang steht (d. h. eine Abstufung innerhalb der Sphäre des Eigenen) sowie eine Art Abstufung des állótpıov (d. h. eine Abstufung innerhalb der Sphäre des Nichteigenen). Das Ganze bildet einen fein- und breitgefächerten Stufenbau des oікع̃ov und des áMóтрıov bzw. dessen, was dem Mittelpunkt des Eigensten ganz nahe oder weniger nahe, ganz enfernt oder weniger entfernt steht. Der fragliche Stufenbau erstreckt sich demnach von dem Eigensten (i.e. dem Mittelpunkt) und dem, was dem Mittelpunkt am nächsten liegt, über die Peripherie der Sphäre des Eigenen und den Teil der Sphäre des Nichteigenen, welcher an die Sphäre des Eigenen grenzt, bis hin zur äußersten Peripherie der Sphäre des Nichteigenen. c) Man darf aber auch nicht vergessen, dass in der stoischen Terminologie das Bedeutungsfeld von oikẽov

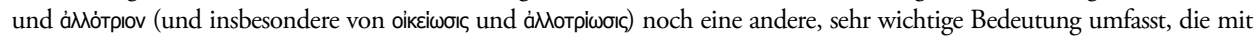
Grundphänomenen zu tun hat, ohne deren Mitberücksichtigung man die Struktur der von einem nichtgleichgültigen

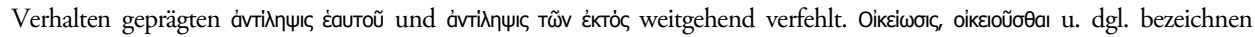

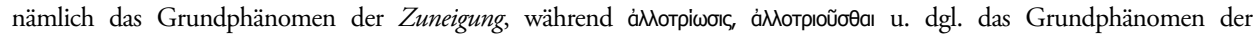
Abneigung nennen. M.a.W.: Das nichtgleichgültige Verhalten, von dem hier immer wieder die Rede war, ist sozusagen in

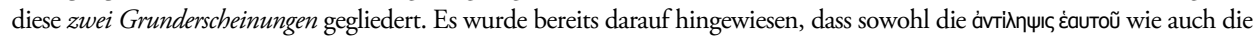

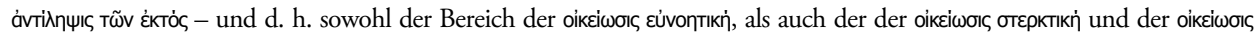
aірєткпं, kurz: das gesamte Wahrnehmungsfeld und alles Wahrgenommene - gleichsam spannungsgeladen und von òpuai (von Neigungen, Strebungen oder Impulsen) durchdrungen sind. Die fraglichen Neigungen, Strebungen oder Impulse sind aber

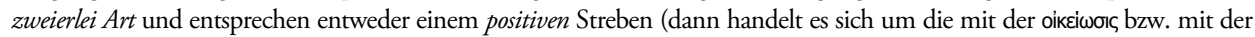

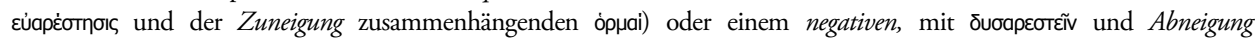
zusammenhängenden Streben - so dass sie ganz im Gegenteil ápoppai darstellen. Daraus folgt, dass auch das

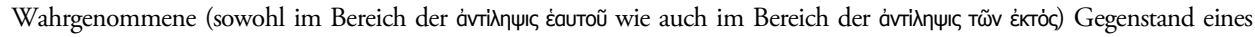

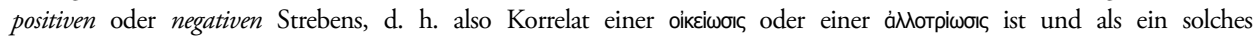
wahrgenommen wird. Es besteht allerdings noch eine dritte Möglichkeit, nämlich, dass es sozusagenn im Zwischenbereich

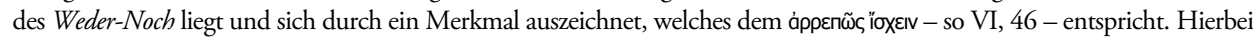
ist aber im Auge zu behalten, dass - wie aus dem Ausgeführten hervorgeht - die fraglichen òpuai und ápopuai bzw. die Art und Weise, wie das Wahrgenommene Gegenstand eines positiven oder negativen Strebens ist, ihrer Intensität nach stark 
Als Fazit bleibt somit festzuhalten: Der Horizont der Wahrnehmung - die von dem Bezug zum gemeinsamen Zentralpunkt des Selbst zusammengehaltene, das Selbst und seine Umgebung umfassende Alleinheit - ist eine Alleinheit der ouvtripnoıৎ, deren Charakter und

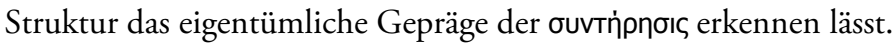

Betrachtet man nun all diese Aspekte etwas näher, so findet man, dass Hierokles doch einen wichtigen Fingerzeig für die Beantwortung der Frage gibt, was die Sphäre des Eigenen zu einer solchen (bzw. was das Selbst zu einem solchen) macht. Denn, fragt man, wie das Selbst beschaffen ist, welches Hierokles zufolge die ausschlaggebende Rolle spielt, von der im Ausgeführten immer wieder die Rede war, so lautet die Antwort: Hierokles' Erörterungen in der ทंӨıкท่ бтохєішбı, heben letzten Endes zwei Grundpfeiler oder Grundbedingungen der

variieren und einen sehr komplexen Stufenbau abgestufter òpuai und abgestufter ápopuai bilden. Wichtig ist aber vor allen Dingen, dass die hier in Frage stehenden Merkmale des Wahrgenommenen (oder, wie man auch sagen kann: die Merkmale, die mit der Art und Weise zu tun haben, wie das Wahrgenommene Gegenstand eines positiven oder negativen, durch eine gewisse Intensität charakterisierten Strebens oder auch für gleichgültig gehalten wird) nicht nur irgendwie ins Gewicht fallen, sondern in der Tat zur Grundbestimmung alles Wahrgenommenen gehören, ja eigentlich das Allerwesentlichste an ihm darstellen. d) Schließlich ist festzuhalten, dass auch dem ganzen Gefüge der abgestuften óppai und ápopuai (und der ihnen entsprechenden, jedem Wahrgenommenen als Gegenstand positiven oder negativen Strebens zukommenden

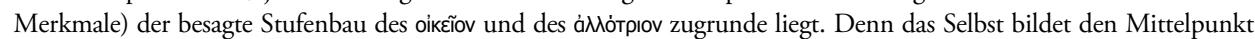
des Spannungsfeldes der ópuai und ápoppai. Das Selbst ist es, das sowohl für die Bestimmung dessen, was zum Gegenstand eines positiven oder negativen Strebens wird, als auch für die Bestimmung der Intensität des fraglichen positiven und negativen Strebens ausschlaggebend ist. Es zeigt sich also, dass auch das Spannungsfeld positiven und

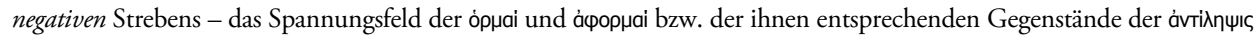

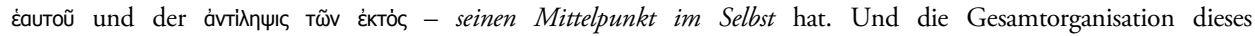
Spannungsfeldes verrät eine durchgehende Rückbezogenheit auf das Selbst. Das positive Streben, das Suchen oder die òpuai

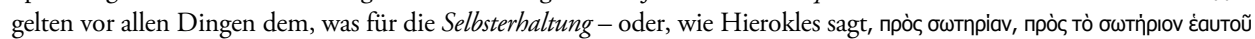
(VII, 46-47) - unentbehrlich, und auch dem, was der Selbstförderung zuträglich ist. Das negative Streben, das Meiden, die àpopuai sind ganz im Gegenteil auf all das gerichtet, was dem Selbst, der Selbsterhaltung oder Selbstförderung schadet.

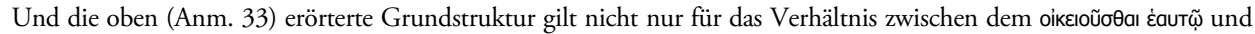

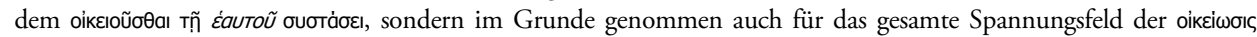

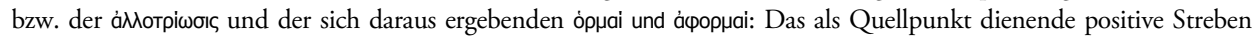
nach Selbsterhaltung und Selbstförderung (und sein Gegenstück, nämlich der Drang, das Gegenteilige zu meiden) streckt gleichsam seine Fangarme ringsumber, so dass aus diesem ursprünglichen, sich „verströmenden“ Kern selbstbezogenen positiven und negativen Strebens abgeleitetes, auf die бúoтaбı gerichtetes, positives und negatives Streben hervorquillt welches abgeleitete Streben sich wiederum „verströmt“ und in positives und negatives, auf diese und jene Gegenstände der äußeren Wahrnehmung gerichtetes Streben mündet, indem diese Gegenstände sich zu der oúotaøıc (zu ihrer Erhaltung und Förderung - und somit zu dem Selbst: zur Selbsterhaltung und -förderung) auf diese oder jene Weise verhalten. Dieses abgeleitete Streben „verströmt“ sich aber auch und mündet wiederum in ein abgeleitetes, positives und negatives Streben sozusagen vierter Ordnung, welches sich auf Gegenstände der äußeren Wahrnehmung richtet,

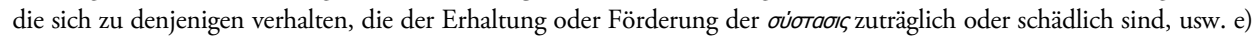

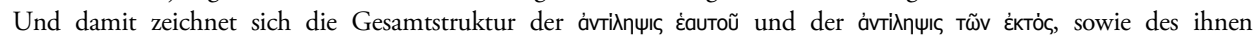
entsprechenden „Wahrnehmungsfeldes“ ab: Eine Art konzentrische Kreise sowohl im Bereich des Eigenen und der

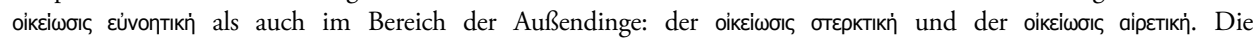

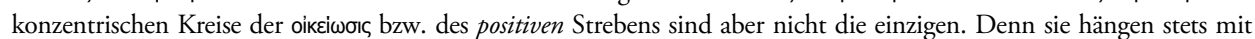

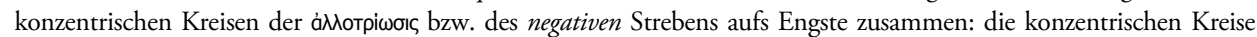

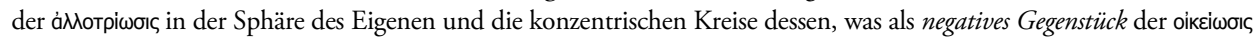

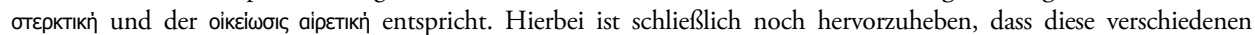

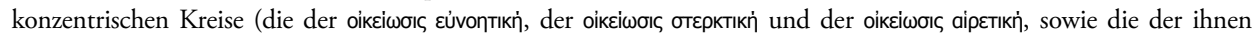
entsprechenden negativen Gegenstücke) nicht voneinander unabhängig sind, sondern vielmehr um den gemeinsamen Mittelpunkt des Selbst kreisen und in dem gleichen Mittelpunkt des Selbst wurzeln - und zwar dergestalt, dass sie miteinander zusammenhängen bzw. ineinander verschachtelt sind und ein einziges, allumfassendes Gesamtgefüge bilden. 


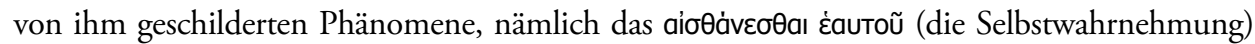

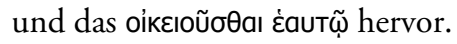

Man kann zwar einwenden, dass Hierokles zufolge das eine aus dem anderen fließt. Die

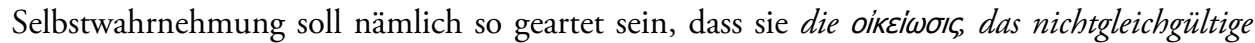
Verhalten zu sich selbst, ja die „Leidenschaft des Selbst“ unweigerlich mit sich bringt ${ }^{38}$. Und es hat demnach keinen Sinn, von zwei Bedingungen zu reden. Hierzu ist nun Folgendes anzumerken. 1. Bei näherem Hinsehen stellt sich heraus, dass Hierokles' Beschreibung der fraglichen Phänomene das Wesentliche verfehlt. Denn es gibt keine solche ununterbrochene

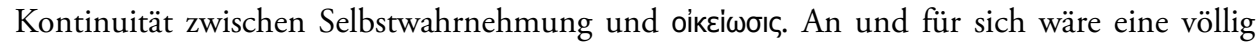
gleichgültige Selbstwahrnehmung (die Selbstwahrnehmung eines „reinen Zuschauers“) durchaus denkbar. Und selbst wenn es zutrifft, dass in manchen Fällen die Selbstwahrnehmung

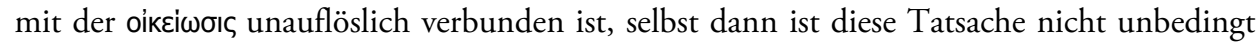

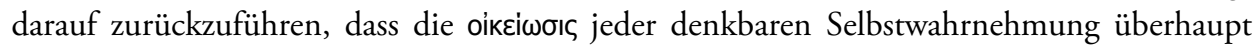
unabdingbar innewohnen muss. Es soll vielmehr untersucht werden, wie die Selbstwahrnehmung beschaffen ist, die dem Wahrnehmenden jegliche Gleichgültigkeit sich selbst gegenüber radikal verunmöglicht und es dazu zwingt, sich von sich selbst berühren zu lassen und sich in dem besagten Sinne seinem eigenen Wesen zu widmen ${ }^{39}$. 2 . Wie dem auch sei, es bleibt die

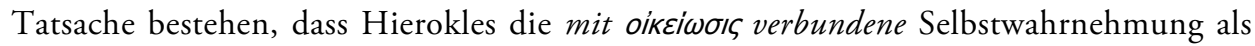
unerlässliche Bedingung der Verfassung des Selbst bzw. der Sphäre des Eigenen nennt, die ihm zufolge den Mittelpunkt des ganzen Horizonts der Wahrnehmung bildet. Und damit hebt er ohnehin beide Aspekte hervor.

Nun, was bedeutet dies? Es bedeutet, dass das Selbst, welches Hierokles zufolge den Mittelpunkt jeder Wahrnehmung darstellt und all den Phänomenen zugrunde liegt, von denen hier die Rede war, ein eigentümliches Verhältnis zu sich selbst voraussetzt, ohne welches

${ }^{38}$ Die Argumentation, die in der Kolumne VI, 27ff. entwickelt wird, soll dazu dienen, diese Grundthese

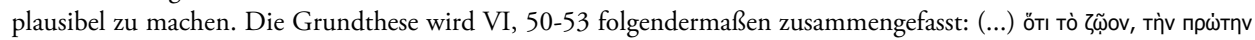

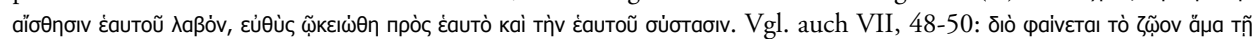

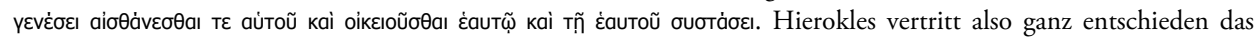

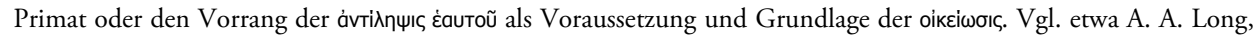
„Hierocles on oikeiosis and Self-Perception“, op. laud., S. $94 \mathrm{ff}$ (252ff), G. Badalamenti, „Ierocle Stoico e il concetto

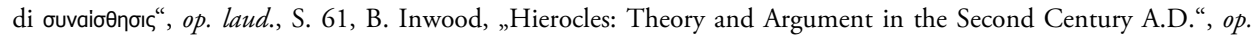
laud., bes. S. $155 \mathrm{ff} ., 169 \mathrm{ff}$.

39 Wenn hier behauptet wird, dass eine völlig gleichgültige Selbstwahrnehmung (die Selbstwahrnehmung eines „reinen Zuschauers") an und für sich denkbar wäre, so bedeutet dies zweierlei: zunächst einmal, dass Hierokles gar nicht gezeigt hat, dass eine solche völlig gleichgültige Selbstwahrnehmung (die Selbstwahrnehmung eines „reinen Zuschauers") an und für sich unmöglich ist, und zum zweiten dass man von keinem Standpunkt weiß, von dem aus die Möglichkeit eines solchen „reinen Zuschauers“ und der ihm entsprechenden völlig gleichgültigen Selbstwahrnehmung apodiktisch ausgeschlossen werden könnte. Die Tatsache bleibt dennoch bestehen, dass jede uns bekannte Wahrnehmung mit Selbstwahrnehmung, ja mit einer nichtgleichgültigen Selbstwahrnehmung zusammenhängt, und zwar dergestalt, dass wir im Grunde genommen von einer gleichgültigen Wahrnehmung überhaupt keine Ahnung haben. Ja, es ist durchaus

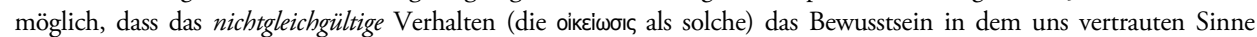

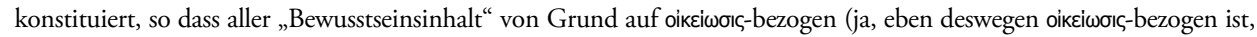

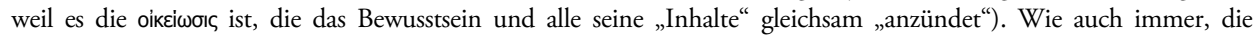
entscheidende Frage ist, man kann es nicht oft genug betonen: Wie ist die Selbstwahrnehmung beschaffen, die dem Wahrnehmenden jegliche Gleichgültigkeit sich selbst gegenüber radikal verunmöglicht und es dazu zwingt, sich von sich selbst berühren zu lassen und sich in dem besagten Sinne seinem eigenen Wesen zu widmen? Das ist die von Hierokles versäumte

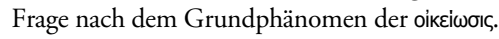


es nicht in der Lage ist, die Funktionen auszuüben, die Hierokles ihm als Grundbedingung und Mittelpunkt der Wahrnehmung zuschreibt. Oder genauer: 1. Das Selbst, von dem Hierokles redet, zeichnet sich gerade dadurch aus, dass es sich insofern zu sich selbst verhält, als es seiner selbst gewahr oder inne wird. Ohne Selbstwahrnehmung gibt es im hierokleischen Sinne kein Selbst. 2. Das Selbst, von dem Hierokles redet, zeichnet sich aber auch dadurch aus, dass es sich noch in einem anderen Sinne zu sich selbst verhält, nämlich indem es sich selbst zugetan und um sich selbst bemüht ist. Ohne dieses nichtgleichgültige Verhalten zu sich selbst gibt es im hierokleischen Sinne kein Selbst.

Hierokles' Erörterung der hier besprochenen Phänomene läuft demnach darauf hinaus, dass das Selbst, welches in der Wahrnehmung sozusagen die Hauptrolle spielt, alles andere als eine selbstverständliche und automatische Folge des Prinzips der Identität darstellt, dem zufolge jedes Seiende mit sich selbst identisch ist. Hierokles' Ausführungen zeigen, dass, selbst zugegeben, dass dem Phänomen, welches den Mittelpunkt des Gesamthorizontes der

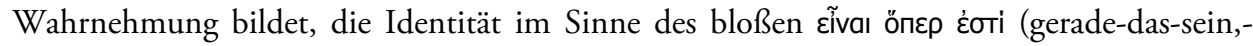
was-es-ist) zugrunde liegt, selbst dann die Identität eines vorhandenen Seienden mit sich

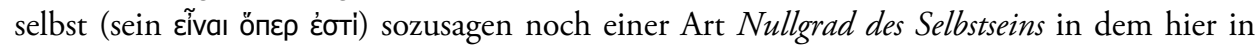
Frage stehenden Sinne - d. h. im Sinne dessen, was als Mittelpunkt der Wahrnehmung fungiert - gleichkommt.

Das Selbst, von dem Hierokles redet, bildet also ein ganz eigentümliches Phänomen. Es ist auf die Identität eines Vorhandenen mit sich selbst völlig unzurückführbar. Es setzt etwas Anderes voraus, und zwar dergestalt, dass dieses Andere in einem Selbstverhältnis oder

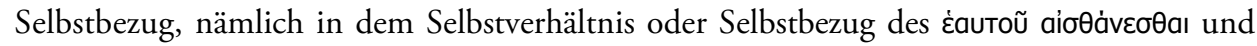

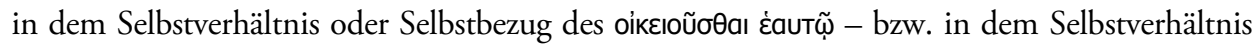

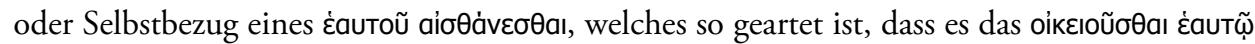
und die бuvтńpпoıs unweigerlich mit sich bringt, gründet. Oder anders gesagt: Das Selbst, von dem Hierokles redet, ist Selbstbezug. Es besitzt an und für sich schon einen selbstbezüglichen, selbstreferentiellen Charakter. Es ist ein sich durch ein eigentümliches Verhältnis oder einen eigentümlichen Bezug zu sich selbst verselbstendes Selbst, oder genauer: ein sich selbstbezüglich zum Selbst Verselbstendes (es sei mir erlaubt an dieser Stelle einen Ausdruck Goethes aus Dichtung und Wahrheit zu benutzen). ${ }^{40}$

Dieser ursprüngliche Selbstbezug - das von Grund auf durch einen Bezug konstituierte, in

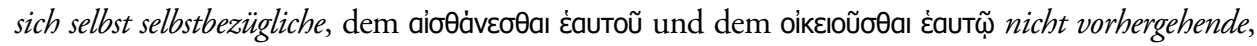

${ }^{40}$ J. W. v. Goethe, Dichtung und Wahrheit, II, 9, J. W. von Goethe Werke (Hamburger Ausgabe), München 1998, Bd. 9, S. 353. Es ist vor allen Dingen festzuhalten, dass das Eigene als solches (bzw. das Selbst als solches) etwas ist, was es im Bereich des bloß Vorhandenen überhaupt nicht gibt. Hier zeichnen sich zwei entgegengesetzte Blickrichtungen bzw. Auffassungen ab. Der ersten - nämlich der landläufigen, zunächst und zumeist herrschenden Auffassung -zufolge setzt das

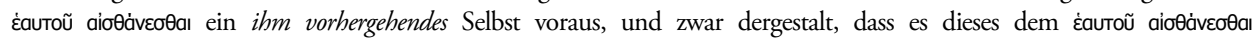

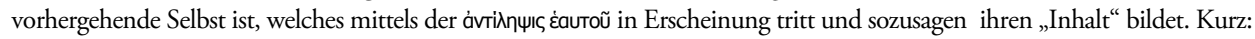

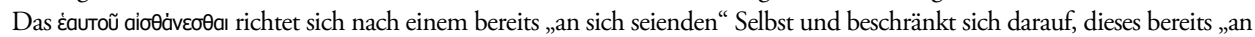
sich“ bestehende Selbst erscheinen zu lassen. Der zweiten Auffassung zufolge ist das Selbst bzw. die Sphäre des Eigenen ganz anders beschaffen: Das Selbst (bzw. die Sphäre des Eigenen) findet nur im Modus des ,als-Selbst“ - eines erst durch

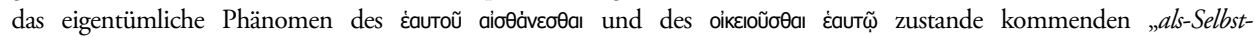
Empfundenwerdens “ - statt. Hierokles' Ausführungen zeichnen sich in dieser Hinsicht durch ihre Zweideutigkeit aus. Denn

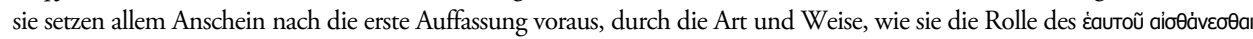

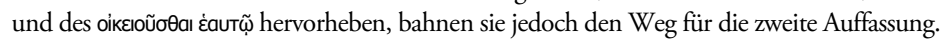




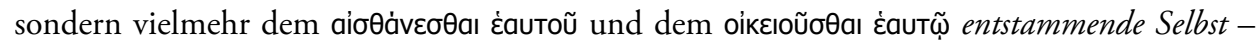
ist es, welches das Gesamtnetz von abgeleiteten Selbstbezügen ermöglicht und gründet, von dem hier die Rede war. M. a. W.: Der ganze Bereich der weiter oben besprochenen Phänomene wurzelt in diesem Kern, und zwar so, dass es dieses ursprüngliche, durch Selbstbezug (den

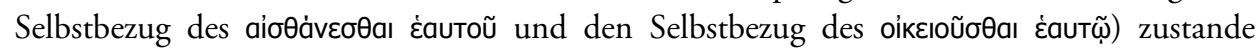
kommende „Sich-Verselbsten“ ist, der die gesamte Sphäre sowohl des Eigenen als auch der äußeren Wahrnehmung eröffnet und durchpulst.

\section{5- Bilanz und Ausblick}

Das ist das Grundergebnis der hierokleischen Erörterung. Es ist allerdings kein Endergebnis. Es verhält sich vielmehr so, dass dieses Ergebnis die Beantwortung aller entscheidenden

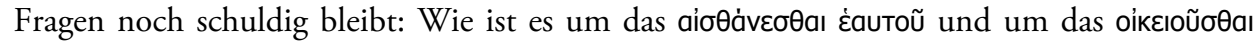
غ̇autụ bestellt? Wie hängt das eine mit dem anderen zusammen? Worin besteht das Selbst als solches? Wodurch zeichnet sich das ihm innewohnende, es konstituierende Selbstbezug aus? etc., etc. Hierokles hält aber an der Schwelle dieser Fragen inne und tut als ob alles im Grunde genommen geklärt und erledigt wäre. Er lässt somit seine Grundbegriffe und das Wesen der von ihm hervorgehobenen Phänomene im Grunde genommen ungeklärt. Wie er auch in einer anderen Hinsicht an der Schwelle der entscheidenden Fragen innehält, nämlich indem er voraussetzt, dass die von ihm dargestellten Phänomene und Strukturen für alle Lebewesen gelten, davon abgesehen, ob es sich um einfachere oder komplexere Lebewesen handelt. M. a. W.: Er setzt eine Art ununterbrochener Kontinuität und Homogenität zwischen allen Lebewesen in der ganzen scala naturae voraus, so dass die Grundstruktur der hier in Frage stehenden Phänomene in allen Fällen die gleiche ist, und sämtliche Unterschiede sowohl zwischen verschiedenen Lebewesen als auch in den verschiedenen

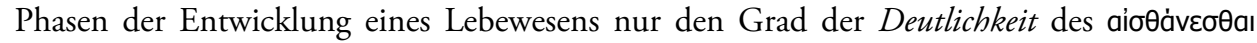

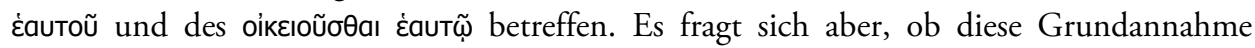
berechtigt ist. Es fragt sich, ob „Selbst“, „Selbstbezüge“ „Wahrnehmung“, „Selbstwahrnehmung“,

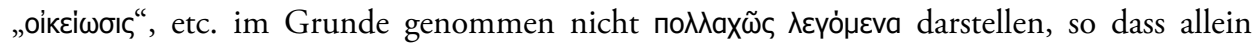
schon die Tatsache, dass man im Singular spricht und Eindeutigkeit bzw. eine Art universeller Affinität aller solcher Phänomene voraussetzt, irreführend, ja so irreführend ist, dass die irreduzible Komplexität vielleicht miteinander zusammenhängender, aber nichtsdestoweniger voneinander stark abweichender Ebenen durch eine solche alles über einen Kamm scherende und unter einen Hut bringende Erörterung gleichsam verschüttet wird.

Es braucht im übrigen kaum betont zu werden, wie sehr die Inangriffnahme solcher Grundfragen der Öffnung des Fasses der Pandora ähnelt ${ }^{41}$.

${ }^{41}$ Hier muss man sich darauf beschränken, das Allerwesentlichste zusammenfassen: a) Hierokles setzt, wie ausgeführt, eine ununterbrochene Kontinuität und Homogenität zwischen allen Lebewesen voraus, so dass die

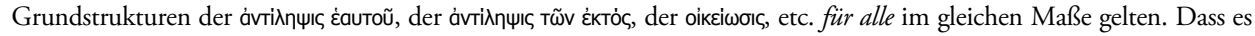
zwischen den einfacheren und den komplexeren Lebewesen erhebliche, ja gewaltige Unterschiede gibt, wird von Hierokles keineswegs ignoriert. Er vertritt aber allem Anschein nach die Auffassung, dass sämtliche derartige Unterschiede (und auch der Unterschied zwischen den verschiedenen Phasen in der Entwicklung eines „höheren 


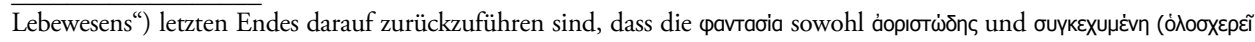

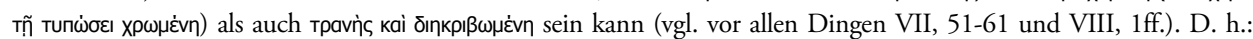

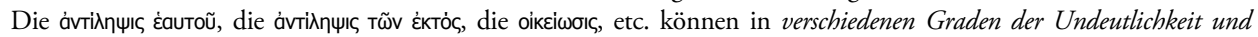

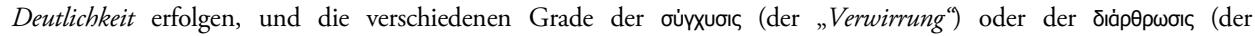

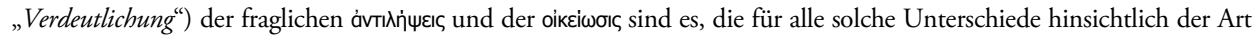

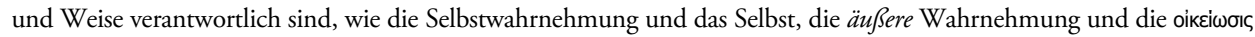
bei den verschiedenen Lebewesen und in den verschiedenen Phasen der Entwicklung eines Lebewesens konstituiert sind. Vgl. beispielsweise H. Schenkl (Hrsg.), Epicteti dissertationes ab Arriano digestae, Leipzig 1916, Ndr. Stuttgart 1965, II, 17 (1, 7, 13, 38), IV, 7, 38, Plutarch, De communibus notitiis adversus Stoicos, 1059b, Seneca, Ad Lucilium epistulae morales, CXXI, 11ff., Seneca, De ira, I, iii, 7, Cicero, Topica 31, Tusculanae 4.53, und etwa A. Bonhöffer, Epictet und die Stoa. Untersuchungen zur stoischen Philosophie, Stuttgart 1890, S. 189, M. Pohlenz, Grundfragen der stoischen Philosophie, Göttingen 1940, S. 82ff., Ders., Die Stoa. Geschichte einer geistigen Bewegung, Bd. 2, Göttingen 1949, S. 33, 164, J. Pinborg, „Das Sprachdenken der Stoa und Augustins Dialektik“, Classica et Mediaevalia 23 (1962), S. 148-177, bes. 153f., V. Goldschmidt, Le système stö̈cien et l'idée de temps, Paris 1979, 4. Aufl., S. $161 f .$, H. Tarrant, „Agreement and the Self-Evident in Philo of Larissa“, Dionysius 5 (1981), S. 66-97, M. Frede, „Stoics and Skeptics on Clear and Distinct Impressions“, in: M. Burnyeat (Hrsg.), The Skeptical Tradition, Berkeley 1983, S. 65-93 (=M. Frede, Essays in Ancient Philosophy, Oxford/Minneapolis 1987, S. 151-176), G. Badalamenti, „Ierocle Stoico e il

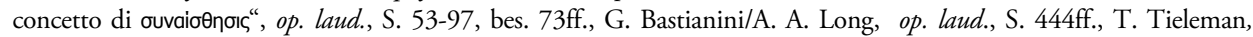
Galen and Chrysippus on the Soul: Argument and Refutation in the De Placitis II-III, Leiden 1996, S. 178, 201f., 229f., 248, C. Brittain, Philo of Larissa, The Last of the Academic Skeptics, Oxford 2001, S. 122, C. Brittain, „Non-Rational Perception in the Stoics and Augustin“, Oxford Studies in Ancient Philosophy 22 (2002), S. 253-308, R. Bees, Die Oikeiosislehre der Stoa, op. laud., S. 31f., 40, 298ff., H. Løkke, „The Stoics on Sense Perception“, in: S. Knuuttila/P.Kärkkäinen (Hrsg.), Theories of Perception in Medieval and Early Modern Philosophy, Berlin 2008, S. 35-46.

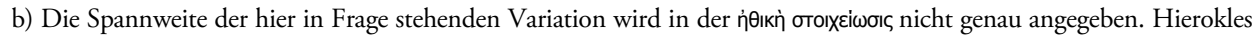

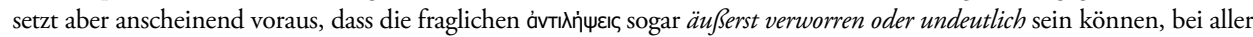
Verworrenheit und Undeutlichkeit jedoch die Fähigkeit nicht verlieren, die Grundfunktionen auszuüben, die von ihm geschildert werden. Dies bedeutet aber, dass, selbst wenn die Frage nach dem Unterschied zwischen Bewusstem und

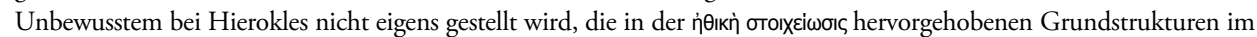
Grunde genommen diesem Unterschied gegenüber indifferent sind. Das Bewusstsein setzt sozusagen nur das mit

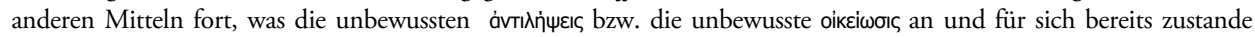
bringen. Insofern spielt der Unterschied zwischen dem Bewussten und dem Unbewussten dieser Auffassung zufolge

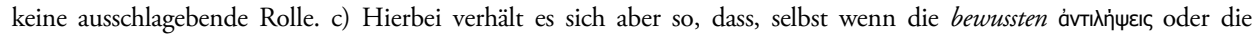

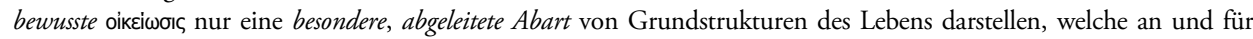

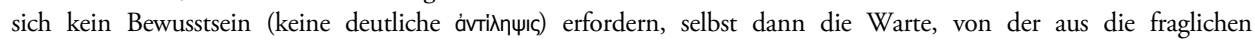

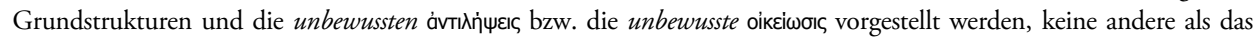

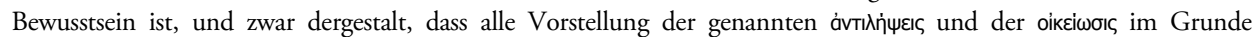

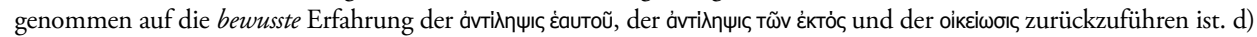
Es ist fraglich, ob die Unterschiede zwischen den einfacheren und den komplexeren Lebewesen auf verschiedene Grade

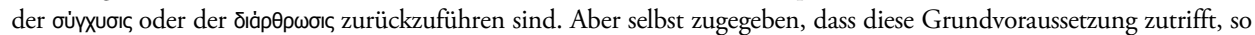

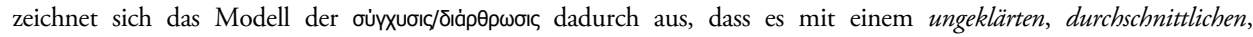

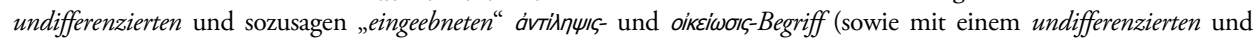
„eingeebneten“ Selbstbegriff) operiert. Dieses Modell setzt sowohl einen gemeinsamen Nenner als auch Unterschiede

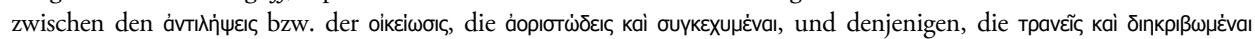
sind, voraus - aber ohne genau zu bestimmen, worin dieser gemeinsame Nenner (der Faden der Kontinuität) und worin die Unterschiede eigentlich bestehen. e) Dieses Manko hängt mit dem Folgenden aufs Engste zusammen. Bei dem Versuch,

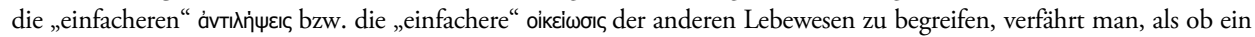
völlig neutraler Standpunkt durch seine reine „Durchsichtigkeit“ befähigt wäre, vom Komplexeren bzw. von der uns eigentümlichen, deutlichen, bewussten Erfahrung abzusehen und einen Einblick in die Beschaffenheit des „Einfacheren“

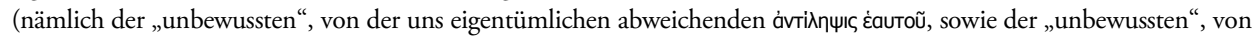

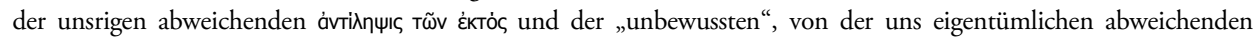

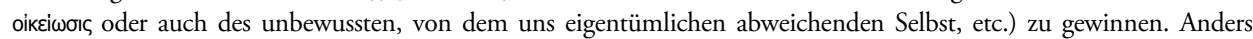
gesagt: Es wird vorausgesetzt, dass wir ohne weiteres in der Lage sind, die Epigenesis der uns eigentümlichen Bewusstseinsform gleichsam rückgängig zu machen und durch eine Art „Abbau“ dieser uns eigentümlichen Bewusstseinsform das, was der fraglichen Epigenesis vorhergeht, als etwas problemlos Zugängliches zu begreifen und 
Die Art und Weise, wie die von Hierokles dargestellte stoische Lehre sich noch als anregend und produktiv erweisen kann, lässt sich demnach in Abwandlung eines Diktums von Goethe über Lichtenberg formulieren. Goethe schreibt nämlich in den Maximen und Reflexionen: „Lichtenbergs Schriften können wir uns als der wunderbarsten Wünschelrütte bedienen: wo er einen Spass macht, liegt ein Problem verborgen. “42 Der von Hierokles dargestellten stoischen Lehre kann man sich auch als einer wunderbaren Wünschelrütte bedienen. Denn wo Hierokles seine weitgehend dogmatischen Feststellungen macht und sie zu einem fertigen Lehrgebäude gestaltet, liegen Probleme verborgen - und zwar so, dass es die stoischen Lehrsätze selbst sind, die, wenn man sie unter die Lupe nimmt und auf ihre wirkliche Aussagekraft hin prüft, ungelöste Schwierigkeiten verraten und zeigen, wo bei näherem Hinsehen noch Widerstand zu finden, und die Sache längst nicht geklärt ist und in der Tat jeden Klärungversuchs spottet. Durch die dogmatischen Ausführungen des Hierokles scheinen gleichsam die Adern dessen hindurch, was noch der Untersuchung harrt, und man kann somit seine Lehrsätze in eine Art Landkarte noch ungelöster Fragen und Ausgangspunkte für ihre Diskussion ummünzen.

nachzuvollziehen. Bei näherem Hinsehen stellt sich jedoch heraus, dass der vermeintliche Einblick in die einfacheren

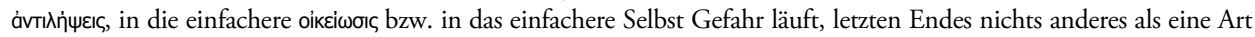

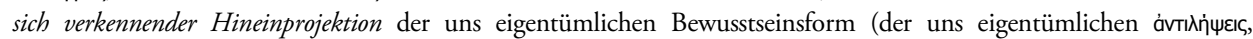

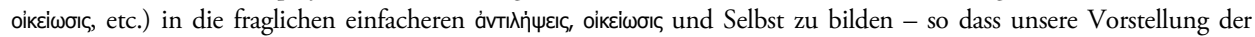

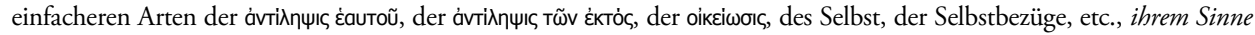
nach zwar den Rückgang auf das Elementare voraussetzt und einen solchen Rückgang für vollzogen hält, in der Tat aber nicht von der Stelle kommt - so dass sie im Grunde nichts anderes als das uns Eigentümliche vorstellt, von dem „Einfacheren“ überhaupt keine Ahnung hat und somit das, was sie zu begreifen beansprucht, vollkommen verfehlt. f) Es

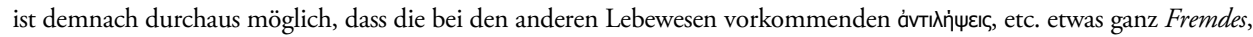
für uns nicht Zugängliches darstellen - jedenfalls etwas ganz Anderes als das, was irrtümlicherweise für eine adäquate Erfassung des in Frage Stehenden gehalten und mit ihm verwechselt wird. Dies bedeutet aber, dass der gemeinsame

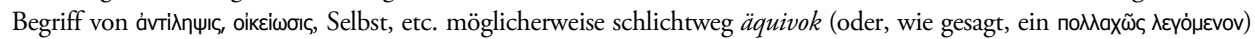
ist. Die hier in Frage stehende Äquivozität zeichnet sich dadurch aus, dass die Reduktion dieser Äquivocität im

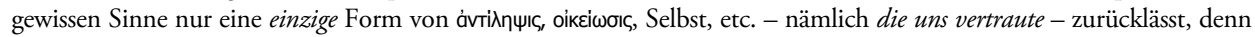
alle anderen bleiben vollkommen unzugänglich und besitzen den Charakter einer Unbekannten. g) Dies bedeutet

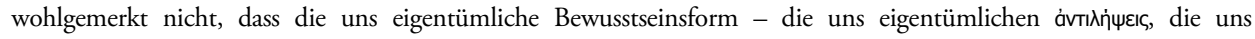

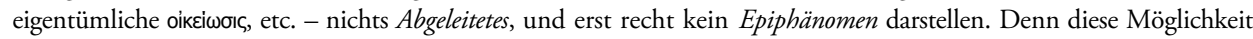
ist im Grunde genommen auch nicht auszuschließen. Es bedeutet nur, dass die fragliche Bewusstseinsform, wenn sie ein Epiphänomen bildet, nicht in der Lage ist, das, dessen Epiphänomen sie ist, adäquat zu erfassen und zu begreifen $h$ ) Die von Hierokles dargestellte Auffassung dieses Problemzusammenhangs sieht indessen von all diesen Fragen ab. Sie ist gerade dadurch charakterisiert, dass sie das ganze Gefüge dessen, was für ein jedes Lebewesen die selbstbezogene,

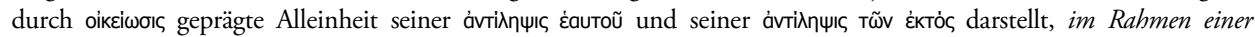
umgreifenden Allnatur, nämlich der vernünftigen, teleologischen Allnatur der Stoiker verstanden wissen will - als ob sie in der Lage wäre, das Ganze von einer Warte aus zu betrachteten, welche zugleich all die verschiedenen selbstbezogenen Kreise der verschiedenen Lebewesen erfassen kann. Mit den soeben genannten Fragen tut sich aber eine Perspektive auf, derzufolge auch das, was jeweils als umgreifende Allnatur vorgestellt wird, letztendlich auf unsere Bewusstseinsform relativ

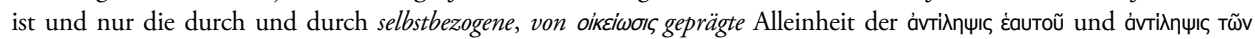
غ̇ктós eines jeden von uns darstellt.

${ }^{42}$ J. W. Goethe, Maximen und Reflexionen, 419, J. W. von Goethe Werke (Hamburger Ausgabe), München 1998, Bd. 12, S. 422 (auch: Aus Makariens Archiv 97, Wilhelm Meisters Wanderjahre III, J. W. von Goethe Werke, Bd. 8, S. 475). 